\title{
DIAMAGNETIC MANIPULATION OF CELL-ENCAPSULATING DROPLETS
}

by

\author{
Stephanie Buryk-Iggers \\ Bachelor of Science, Trent University, 2016
}

A thesis

presented to Ryerson University

\author{
in partial fulfillment of the \\ requirements for the degree of \\ Master of Applied Science in the program of \\ Biomedical Engineering
}

Toronto, Ontario, Canada, 2019

(C)Stephanie Buryk-Iggers, 2019 


\section{AUTHOR'S DECLARATION FOR ELECTRONIC SUBMISSION OF A THESIS}

I hereby declare that I am the sole author of this thesis. This is a true copy of the thesis, including any required final revisions, as accepted by my examiners.

I authorize Ryerson University to lend this thesis to other institutions or individuals for the purpose of scholarly research

I further authorize Ryerson University to reproduce this thesis by photocopying or by other means, in total or in part, at the request of other institutions or individuals for the purpose of scholarly research.

I understand that my thesis may be made electronically available to the public. 
Diamagnetic manipulation of cell-encapsulating droplets

Master of Applied Science, 2019

Stephanie Buryk-Iggers

Biomedical Engineering

Ryerson University

\begin{abstract}
In this thesis, a microfluidic method for label-free control of cell encapsulating droplets is developed using diamagnetic forces. To generate droplets in a microfluidic device, we use a symmetrical flow-focusing design, where two streams of a continuous phase shear a single stream of a droplet phase, resulting in droplet generation. First, it is shown that by adjusting only the droplet phase flow rate, precise control of empty droplets can be achieved. Human prostate cells are then introduced to the system and encapsulated by droplets. Control of the cell-encapsulated droplets and empty droplets is studied. It is shown that cell-encapsulated droplets and empty droplets deflect by different amounts when exposed to the magnetic field. By exploiting this difference, efficient sorting of empty droplets from cell-encapsulated droplets is achieved at a purity of $85 \%$ in a single pass. Following sorting, cells are analyzed and show 90\% viability after a two-hour incubation period.
\end{abstract}




\section{Acknowledgments}

My time at Ryerson University has brought many influential and important people into my life. First and foremost, I would like to thank my advisor, Dr. Scott S. H. Tsai, for his guidance and mentorship. I am so grateful that, as a student coming from outside the field of engineering, he welcomed me into his Laboratory of Fields, Flows, and Interfaces (LoFFI) and supported my growth and learning in the emerging and exciting field of microfluidics. His dedication, encouragement, and support of my research, personal growth, and professional development have been invaluable. His curiosity and enthusiasm for learning and discovery will continue to inspire my approach to research and life.

From the first day of my graduate studies, I had the absolute privilege to learn from and to be supported by my colleague, Niki Abbasi. Leading by example, the passion and commitment that Niki carried for our lab inspired me to continuously grow and improve. Her ongoing support in my learning as a student and in my growth as a scientist was invaluable and I attribute much of my work to her mentorship.

I would like to thank Jennifer Kieda for joining me in my journey of learning, stumbling, and growing during my graduate studies. Thank you for your company and troubleshooting during those long hours in the microfluidic room, and for your ongoing support while I took time to grow my family. 
Thank you to all of my current and former colleagues at LoFFI. You are an unstoppable force of scientific minds, teammates, and friends. I would like to thank each one of you for your ongoing support, kindness, and friendship throughout the years: Vaskar Gnyawali, Morteza Jeyhani, Maryam Navi, Huma Inayat, Ali Salari, Jiang Xu, Katherine Chan, Lianne So, Risavarshni Thevakumaran, and Ali Saremi.

Outside of the lab, I would like to thank my close friends and siblings for being my champions during large and unconventional transitions in my life: Elizabeth Buryk, Niall Buryk, Deirdre Buryk, Natalia Constantinescu, Nicole Walton, Jessica Smith-Cross, Sarah Lalor, Jules Porter and the 2014 Right To Play PLAY team.

I would like to thank my mother for being the most influential role model in my life. As mother, as a wife, as a businesswoman, and as a leader in the field of health care, you inspire me everyday to grow, learn, and exceed expectations.

Lastly, and most significantly, I would like to thank my family. My husband Adam, whose own brilliant mind and commitment to personal growth not only inspired me to begin this journey but teaches me to redefine my limits everyday. During my time at Ryerson, the work I produced and the learnings I gained were only made possible by his endless support and love. My son Theo inspires me everyday to grow, to learn, and to do it all with a smile. Thank you for always greeting me with unconditional love even after long hours at the lab, or time spent travelling away from home. Being your mom is my greatest achievement. 


\section{Dedication}

To my father, Michael Buryk (1950-2010). May this piece of work be one of the many extensions of the love and energy you brought to this world, and to those that had the gift of knowing you. 


\section{Table of Contents}

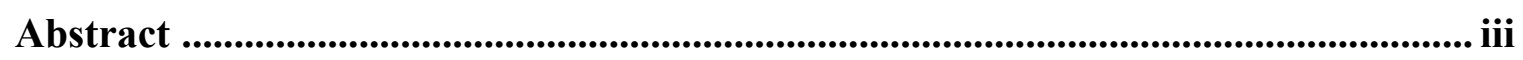

List of Figures ........................................................................................................................ viii

Nomenclature ..............................................................................................

Chapter 1: Concepts and Motivation .................................................................1

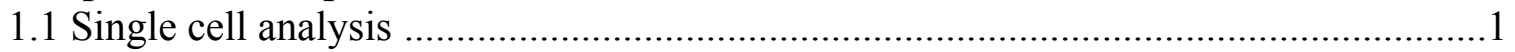

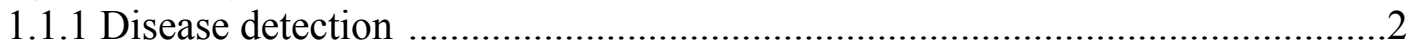

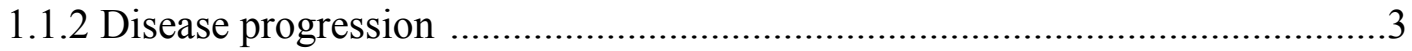

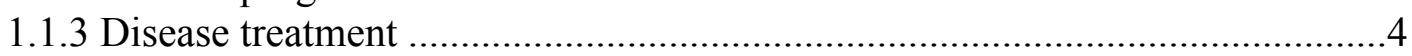

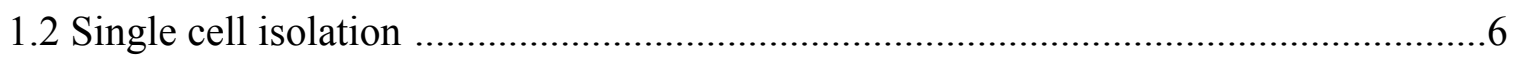

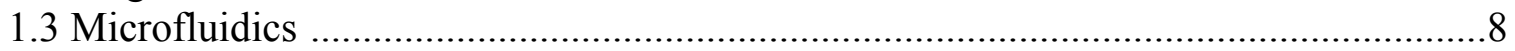

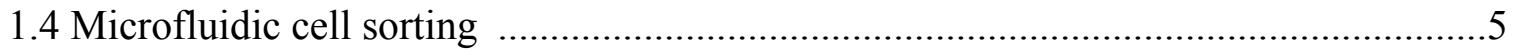

1.5 Microfluidic magnetophoretic cell sorting............................................................ 12

1.5.1 Paramagnetic microfluidic systems ..........................................................13

1.5.2 Diamagnetic microfluidic systems …………...........................................14

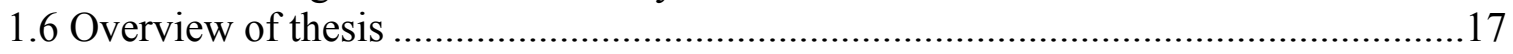

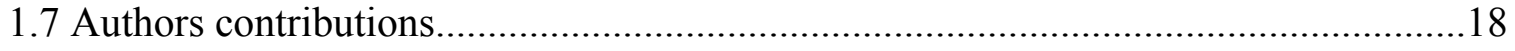

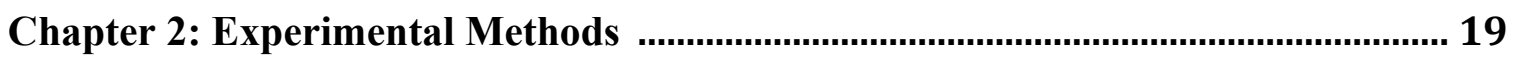

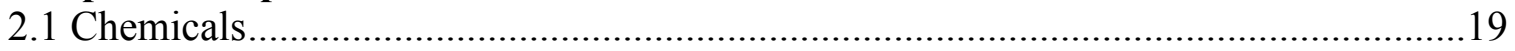

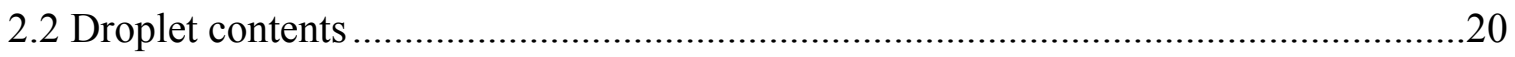

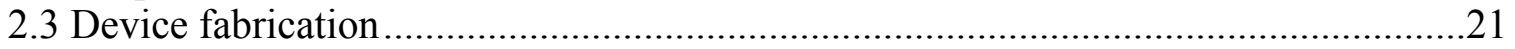

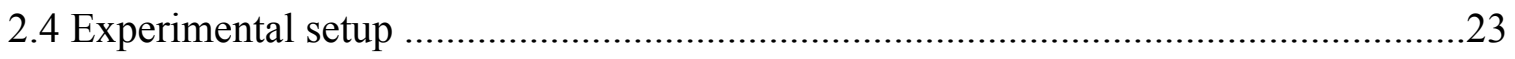

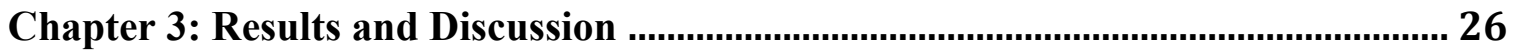

3.1 Diamagnetic droplet deflection ......................................................................26

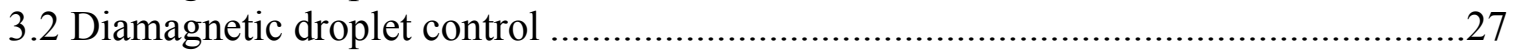

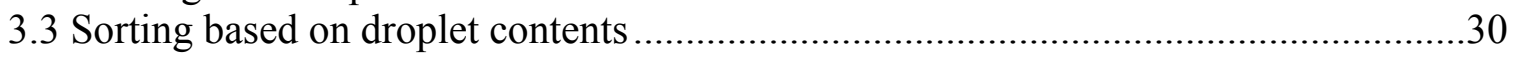

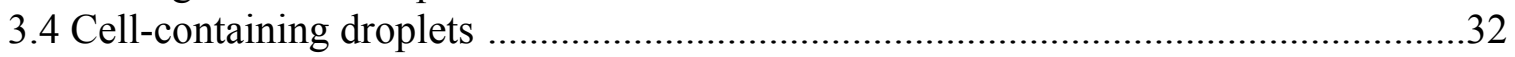

3.5 Single cell fluorescence-based and direct-count assay ..................................................34

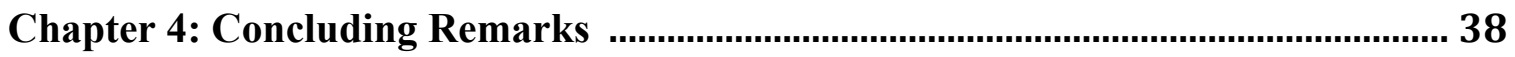

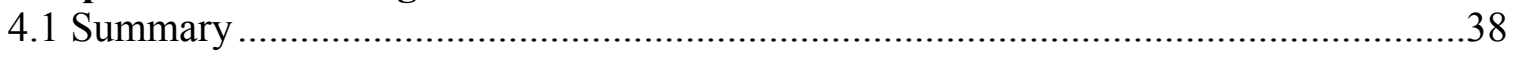

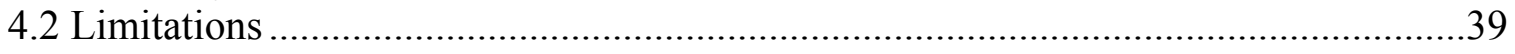

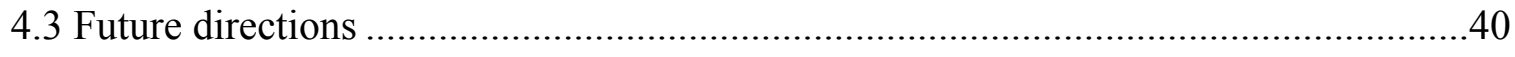

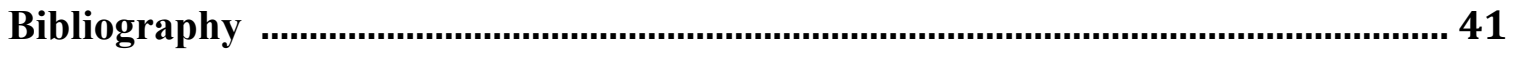




\section{List of Figures}

1.1. (a) Schematic of a microfluidic device employing electrophoresis for cell manipulation. (b) No electric filed applied to the device. (c) Electric field applied to the device. Cell movement from its original stream is observed

1.2. Optical switch located in a microfluidic cell sorting junction. Following analysis by fluorescence, target cells are directed by a laser to the desired outlet. Remaining cells flow to the waste chamber.

1.3. Dielectrophoretic force is applied to a blood sample within a microfluidic device. The larger non-platelet-cells and the smaller platelet cells deflect differently when exposed to an inhomogeneous electric field. The different sized cells are sorted downstream.

1.4. Schematic of magnetophoretic microfluidic device. Sample mixture of magnetic labeled macrophage cells $\left(\mathrm{M}_{\mathrm{a}}\right)$, magnetic labeled HeLa cells $\left(\mathrm{M}_{\mathrm{b}}\right)$, and nonmagnetic particles are introduced together into the device in the $\mathrm{x}$-direction. The sample travels through a separation chamber. A magnetic field is applied in the ydirection. Magnetic labeled cells are deflected from their laminar flow towards the magnetic field gradient. Non-magnetic particles continue in the direction of their laminar flow.

1.5. Schematics of ferrofluid magnetite particles and surfactants at the molecular level. (a) Molecular structure of magnetite. $\mathrm{Fe}^{+3}$ is represented by circles of two sizes. The smaller circles represent iron in tetrahedral coordination, and the large representing octahedral coordination. (b) Illustration of an aqueous ferrofluid stabilized by a surfactant, tetramethylammonium hydroxide. The surfactant particles adhere to the surface of the magnetitie particles. The magnetite particles experience repulsion from one another and the colloid is stabilized.

1.6. Schematic representation of a homogeneous sample of cells traveling through a microfluidic device. (a) Cell mixture enters the device and all cells exit the same outlet when no magnet is applied. (b) Cell mixture enters the device. Cells deflect differently when exposed to a magnetic field, and exit through different outlets. ..14

2.1. Schematic diagram of the microfluidic system with a flow-focusing geometry. Continuous phase consisting of magnetic ferrofluid, mineral oil, and $2 \mathrm{v} / \mathrm{v} \%$ Span 80 is introduced to oil inlet 1 and oil inlet 2, Disperse phase of RPMI 1640 and PC3 cells are introduced to the aqueous inlet. Empty droplets and cell-containing droplets are generated at the flow-focusing junction. The application of a 
permanent magnet attracts the magnetic continuous phase, while diamagnetically deflecting both empty and cell-containing droplets. The encapsulation of cells in the droplets results in an increase in droplet diameter. The amount of droplet deflection is positively related to the size of the droplet diameter.

3.1. Time series images of glycerol droplets captured sequentially downstream the main channel in a continuous phase of ferrofluid. (a) Magnetic field is applied at a magnet distance $1_{\mathrm{m}}=1.1 \mathrm{~mm}$ and droplets are sorted into the upper outlet (b) Magnetic field is not applied to the system and droplets are sorted into the lower outlet. Deflection of the glycerol droplets is observed with magnetic field applied.

3.2. A plot of the deflection distances of droplets with respect to four consecutive distances of the magnet $\left(1_{m}\right)$ from the channel wall. The deflected droplet distances are measured at two continuous-phase flow-rates $\left(Q_{c}=18 \mu \mathrm{L} / \mathrm{min}\right.$ represented by the filled data points and $Q_{c}=35 \mu \mathrm{L} / \mathrm{min}$ represented by the empty data points). For each continuous-phase flow-rate, droplet deflection distance is measured for two trials of differing disperse-phase flow rates in $\mu \mathrm{L} / \mathrm{min}$ (disperse phase high and disperse phase low). The droplet deflection distance $(\Delta y)$ represents the difference between the controlled droplet distance from the channel wall (without a magnetic field applied) from the experimental droplet distance from the channel wall (with magnetic field applied). Droplet deflection distances generally decreased with increase in magnet distance, and with decrease in droplet diameter $(\mathrm{dm})$ measured in $\mu \mathrm{m}$. Error bars indicate the distribution of droplet deflection. Scale bar: $100 \mu \mathrm{m}$. An analysis of variance showed that the effect of $\ell_{m}$ on $\Delta y$ was significant, $F(3,4)=$ $0.56, \mathrm{P}=0.05$.

3.3. The application of a magnetic field on the effect of sorting particle-containing droplets and empty droplets into downstream outlets. (a) Percent of particlecontaining droplets and empty droplets that exit through each outlet when no magnet is applied. (b) Percent of particle-containing droplets and empty droplets that exit through each outlet when a permanent magnet is applied at $1_{m}=1.1 \mathrm{~mm}$. (c) Image series of particle-containing droplets captured downstream of main channel in a continuous phase of ferrofluid. Magnetic field is not applied to the system. Particle-containing droplets and empty droplets sort into outlet 1 (d) Magnetic field is applied at a magnet distance $1_{m}=1.1 \mathrm{~mm}$. Sorting of particlecontaining droplets and empty droplets into different outlets is observed with magnetic field applied. Scale bar: $100 \mu \mathrm{m}$.

3.4. The application of a magnetic field on the effect of sorting cell-containing droplets and empty droplets into downstream outlets. (a) Percent of cell-containing droplets and empty droplets that exit through each outlet when no magnet is applied. (b) Percent of cell-containing droplets and empty droplets that exit through each outlet when a permanent magnet is applied at $1_{m}=1.1 \mathrm{~mm}$. Sorting of cell-containing 
droplets and empty droplets into different outlets is observed with magnetic field applied. (c) Image series of cell-containing droplets captured downstream of main channel in a continuous phase of ferrofluid. Magnetic field is not applied to the system. cell-containing droplets and empty droplets sort into outlet 1 (d) Magnetic field is applied at a magnet distance $1_{m}=1.1 \mathrm{~mm}$. Sorting of cell-containing droplets and empty droplets into different outlets is observed with magnetic field applied.

3.5. (a) The viability of PC-3 cells in different media is compared over time. Cells are incubated in RPMI as the control trial, and the EMG 408 ferrofluid as the EMG 408 trial. In the RPMI droplet trial, cell-containing RPMI droplets surrounded by oilbased ferrofluid are removed from the system and the encapsulated cells are analyzed for viability. (b) Cell viability was determined by adding Calcein AM and EthD-1 to the cell suspension and conducting a fluorescence viability assay. Viability was assessed at 0 hour, 1 hour, and 2 hour marks. The non-viable cells are imaged in red and the viable cells are imaged in green. Viability of PC-3 cells in control RPMI media and the RPMI droplets in oil-based ferrofluid is observed up to 2 hours. EMG 408 shows poor biocompatibility for PC-3 cells, resulting in nonviable cells. (c) Cell-containing droplet surrounded by oil-based ferrofluid that has been removed from the system for assessment of viability. Error bars represent one standard deviation from two different viability tests. 


\section{Nomenclature}

\section{Chapter 1}

Symbol

Re

$\mathrm{Pe}$

$\mathrm{Ca}$

\section{Chapter 2}

Symbol
$\ell_{m}$
$\Delta y$
$d_{m}$
$\chi_{m}$
$\chi_{p}$
$V$
$B$
$\nabla B$
$Q d$
$Q c$

\section{Meaning}

Reynolds number

Péclet number

Capillary number
Meaning

Magnet distance

Change in deflection

Diameter

Magnet susceptibility of magnetic phase Magnet susceptibility of aqueous phase Volume

Magnetic flux density

Magnetic field gradient

Disperse phase flow rate

Continuous phase flow rate 


\section{Chapter 1}

\section{Concepts and Motivations}

\subsection{Single cell analysis}

One of the keys to understanding the progress of disease is the study of individual cells. Conventional laboratory tests, such as enzyme-linked immunosorbent assays, ${ }^{1}$ PCR for transcriptional profiling, ${ }^{2}$ and assays of proliferation activity ${ }^{3}$ build the molecular profile of a cell type based on the average responses of a large population of cells. ${ }^{4}$ However, many diseases, such as cancer, can exhibit intra-population heterogeneity at the cellular level. Thus, when cells are studied as a group, many key molecular properties that can influence the diagnosis, progression, or treatment of a disease can be missed. ${ }^{5}$ In response to this challenge, single cell analysis is used to determine key molecular properties of individual cells from a cell population. When isolated, individual cell profiling can provide noninvasive biomarkers that allow for the early detection of disease, disease progression, and prediction of treatment response.

\subsubsection{Disease detection}

During the growth of a primary tumour, single cells are released into the bloodstream, known as circulating tumour cells (CTCs). ${ }^{6}$ The identification and analysis of rare CTCs 
in a heterogeneous blood sample can provide early diagnosis and prognosis of invasive cancers. ${ }^{6}$ For example, through the isolation and analysis of CTCs from patients with neuroendocrine tumours, Khan et al. (2013) found the presence of CTCs to be associated with decreased survival rates, and increased tumour grade. ${ }^{7}$ In addition, Cristofanilli et al. (2005), found the presence of CTCs to be a predictive indicator of the overall survival of patients with metastatic breast cancer. ${ }^{8}$ Patients with $\geq$ five CTCs in a $7.5 \mathrm{~mL}$ whole blood sample had a median overall survival of 18 months verses those with $<$ five CTCs, who had an overall survival of 14.2 months. ${ }^{8}$ Similarly, CTC levels have been found to be strong predictors of survival for patients with colorectal cancer. ${ }^{9}$ Cohen et al. (2008), found that patients with $\geq$ three CTCs in a $7.5 \mathrm{~mL}$ whole blood sample had an overall survival of 9.4 months, verses those with $<$ three CTCs who had an overall survival of 18.5 months. ${ }^{9}$ Through these examples it can be seen that the study of individual cells from within a greater cell population can inform the detection and grade of disease.

\subsubsection{Disease progression}

Following isolation of target cells, subsequent analysis of single cells can be used to predict progression of disease. Lohr, et al. (2014), isolated CTCs from blood samples and using single cell genomic analysis, the genetic expression profile of CTCs were compared to that of cells from a primary pancreatic tumour. ${ }^{10}$ It was found that the expression of a specific gene, WNT2 gene, in pancreatic cancer cells is associated with an increase in metastasis. Thus demonstrating that the genomic analysis of single cells can be used to inform and better predict the progression of disease. Additionally, Gammal et al. (2010) employed single cell genomic analysis to determine the 
significance of a $8 \mathrm{p}$ gene deletion and $8 \mathrm{q}$ gene gain commonly observed in prostate cancers. Through this study, it was found that the frequency of the 8q gene gain in metastatic tumours increased significantly when compared to that of the primary tumour. These findings suggest that the $8 \mathrm{q}$ gene is relevant in the progression of prostate cancer towards deadly late stages. ${ }^{11}$

\subsubsection{Disease treatment}

In addition to the detection of disease and predicting the progression of disease, single cell analysis can also inform approaches to treatment. Mutations and epigenetic changes in the genome of cancer cells provide mechanisms to sustain stresses induced by therapeutic drug treatment. ${ }^{12}$ Such changes in target cells bring resistance to specific drugs, thereby disrupting the efficacy of cancer treatment. A formative question in the field of cancer treatment is whether these resistance mutations are pre-existing before treatment or if they emerge in response to therapeutic agents. To inform treatment strategies, the genomic evolution of cancer cells is conventionally monitored using repeat biopsies and bulk cell analysis. However, this process can be difficult as it is invasive for the patient and can be confounded by intra-tumour cellular heterogeneity. ${ }^{12}$ As a result, repeat single cell genomic analysis has emerged as an alternative method. ${ }^{13}$ Through the development of a whole-genome single cell sequencing method, Wang et al. (2014) measured the precise mutation frequencies of single cells of two types of breast cancer tumours; estrogen-receptor-positive $(\mathrm{ER}+)$ breast cancer and a triple-negative ductal carcinoma. Using this approach, it was found that most mutations found in these two 
cancer types are pre-existing in the tumour mass before chemotherapy. ${ }^{13}$ Therefore, the subclones observed are the result of high mutation rates and not selective pressures in response to a therapeutic agent. ${ }^{13}$ Conversely, cancer cells have also demonstrated genomic mutations to sustain stresses induced by chemotherapeutic drugs. ${ }^{12}$ Wilson et al. (2012) observed the mutation of a specific gene, Ras gene, following exposure to drugs

that targeted tyrposine kinase receptors. ${ }^{14}$ As a result, cells were resistant to tyrosine kinase receptor inhibition, which rendered the treatment ineffective. From these examples it is shown that single cell sequence analysis can reveal preexisting or induced molecular heterogeneity existing in individual tumours. Thus demonstrating that targeted and effective cancer treatment is dependent on the analysis of the phenotypes and genotypes of individually isolated cells.

\subsection{Single cell isolation}

A well-established technique for cell sorting is centrifugation. Typical centrifugation can be used to separate the constituents of raw blood. ${ }^{15}$ Following centrifugation, raw blood is separated based on cell density into three layers. Red blood cells lay on the bottom of tube, nucleated cells form a ring above the red blood cells, with the top layer comprised of blood plasma. Centrifugation provides an approach to cell sorting that is efficient and user-friendly, however, it can apply mechanical stress on cells that modify their phenotype. ${ }^{16}$ In addition, this approach relies solely on cell density and thus cannot isolate and sort individual cells from a bulk rare sample based on any other distinguishing parameters. ${ }^{16}$ 
As an alternative, membranes can be used to sort cells based on their size and deformability. An example of a commonly used membrane is the polycarbonate Isolation by Size of Epithelial Tumor-cells membrane (ISET). ${ }^{17}$ The ISET is calibrated with cylindrical membrane pores measuring $8 \mu \mathrm{m}$ in diameter. When blood is flushed through the membrane, red blood cells pass through easily, white blood cells deform and also pass through pores, while the larger epithelial tumor cells are unable to pass through the membrane. Membranes provide a cost-efficient platform for cell sorting, however, the need to process each membrane, as well as frequent clogging of the membrane can lead to an overall cumbersome and time-intensive process. ${ }^{18}$

Flow cytometry has provided an effective and widely used platform for cell sorting. When combined with fluorescence staining and downstream sorting mechanisms, a flow cytometer can sort sells based on fluorescence emitted, as well as the observed forward and side scatter signals. ${ }^{19}$ Within this platform, cells are suspended in a fluid and individually passed through a laser beam. The emitted light scatter and fluorescence emission signals are digitized and provide information on cell classification. Droplet containing cells are then sorted based on a specified sorting criteria using electrostatic deflection. $^{20}$ This approach, however, is limited by the platform's size, price, and complexity. In addition, it is frequently subject to nozzle clogging, high reagent consumption and cross-contamination due to sample carry-over. ${ }^{18}$

In exploring the traditional approaches, it is evident that cell sorting is limited by required technical expertise for operation, large and bulky instrumentation, cost efficiency, and 
high operating pressures or labeling steps that can result in a loss of cell function or reduced cell viability. Consequently, microfluidic platforms have emerged as the next generation of cell sorting devices. ${ }^{21}$ One of the leading advantages of microfluidic platforms is the integration of multiple systems, steps, and bulky instrumentation into a single chip, allowing for the parallelization of cellular isolation, analysis, and experimental processing. ${ }^{21,22}$ In addition, the reduction in equipment size allows for a reduction in required sample size, sample treatment time on-chip, reagent consumption, and chemical waste. ${ }^{18}$ Lastly, microfluidic devices experience unique physical phenomena such as fluids exhibiting Stokes flow. In this state, mixing of fluids and the manipulation of cells can be carefully controlled. ${ }^{23}$

\subsection{Microfluidics}

The field of microfluidics first emerged less than three decades ago, but has since seen rapid adoption in areas of microbiology and cell sorting. ${ }^{24,25}$ In a microfluidic system, small amounts of fluids and biological particles are manipulated in a series of channels with dimensions of tens to hundreds of micrometers. ${ }^{26}$ One of the leading contributions to the growth of microfluidics was the advancement of microfabrication techniques. Particularly, the technique of soft lithography increased the accessibility of this platform to researchers. ${ }^{27}$ When considering microbiology, soft-lithography fabrication techniques allow for the replication of structures that match the intrinsic scale of cells. With this, researchers can study the relationship between the shape of cells, the mechanical properties of cells, and the role of physical forces in the differentiation of cells. ${ }^{28}$ 
With the growth of microfluidics, typical wet-bench laboratory operations can now be fully performed on micro-scale setups known as lab-on-a-chip (LOC) systems. ${ }^{7,29,30}$ LOC systems offer advantages over traditional wet-bench setups. The reagent volumes used, as well as the volume of waste produced are significantly reduced when compared to a macro-scale set-up. ${ }^{31}$ Therefore, the cost associated micro-scale experiments, as well as the sample volumes required are reduced. A powerful application of LOC systems is its role in improving health in underdeveloped countries around the world. The actuation of fluids, biological sample separation, disease marker amplification, and disease marker detection have been integrated into a single LOC device, allowing for user-friendly and cost effective diagnostic tools. ${ }^{32}$

When working on a micro-scale, the change in fundamental physics of fluid must be considered. The fluid physics of a microfluidic system is dictated by a competition between various physical phenomena, which is expressed using a series of dimensionless numbers. One of the most commonly mentioned dimensionless numbers in connection to microfluidics is Reynolds number $(R e)$, representing the ratio of inertial and viscous force. ${ }^{23}$ When $R e$ is very small $(R e<<1)$ the viscous forces overwhelm inertial forces, and it results in linear and predictable Stokes flow. ${ }^{33}$

In Stokes flow that arises with a low Re, phase mixing occurs by diffusion alone. While the resulting lengthy mixing times can allow for precise control, it can also lead to experimental challenges. For example, chemical reactions in microfluidic devices often require different reagents to be mixed rapidly. Therefore, controlling dispersion in a 
microfluidic device can be of great importance. The dimensionless Péclet number $(\mathrm{Pe})$ expresses advection relative to diffusion. Diffusion can be defined as the random motion of molecules in their surroundings, and advection can be considered the transport of molecules as a result of the surrounding fluid's motion. ${ }^{34}$ Therefore, molecules in a solution in the presence of a flow will be both transported by the flow, as well as diffused throughout the solution. Surface tension has also been shown to profoundly influence fluid behaviour in microfluidic systems. Capillary number $(\mathrm{Ca})$ is the dimensionless measure of viscous force relative to interfacial tension force ${ }^{35}$ Surface properties are thus often selected to influence the $C a$ number. Surface tension is the result of cohesive forces among liquid molecules and their interaction at an interface. As the value of surface tension increases, liquid molecules work to minimize their surface area resulting in molecules pulling away from the interface and towards the bulk liquid. ${ }^{36}$ Through the addition of surfactants, we can see a decrease in surface tension and a resulting increase in the $C a$ number. ${ }^{37}$ The important dimensionless parameters of $R e$, $P e$, and $\mathrm{Ca}$ can thus be used to explore fluid behavior on a scale where viscous drag, diffusion, and surface tension can dominate.

\subsection{Microfluidic cell sorting}

Microfluidic devices offer a miniaturized platform for spatial and temporal control on a cellular scale. ${ }^{29,38}$ Microfluidic-based flow cytometers have emerged to provide a relatively cheap and portable alterative to its conventional counterpart. In addition, this platform removes the need for aerosol droplets, and limits both the reagent volumes

required and the occurrence of cross-contamination. ${ }^{39}$ Following cell characterization, 
cell sorting can be achieved using a variety of mechanisms including electrophoresis and optical sorting. When using electrophoresis in a microfluidic device, the application of an electric field can be used to control cells. Cells are suspended in a carrier fluid, travel through a microchannel, and are then exposed to an electrophoretic field gradient. ${ }^{40}$ With the majority of cells possessing a slight negative charge on their surface, they will migrate towards a positive electrode and away from their original streamline (Figure 1.1). ${ }^{41}$ Although an effective cell sorting technique, the generation of an electrical field can cause Joule heating near the electrodes, which can lead to harmful effects on the sample cells such as modification of cell phenotype, or cell-death. ${ }^{42}$

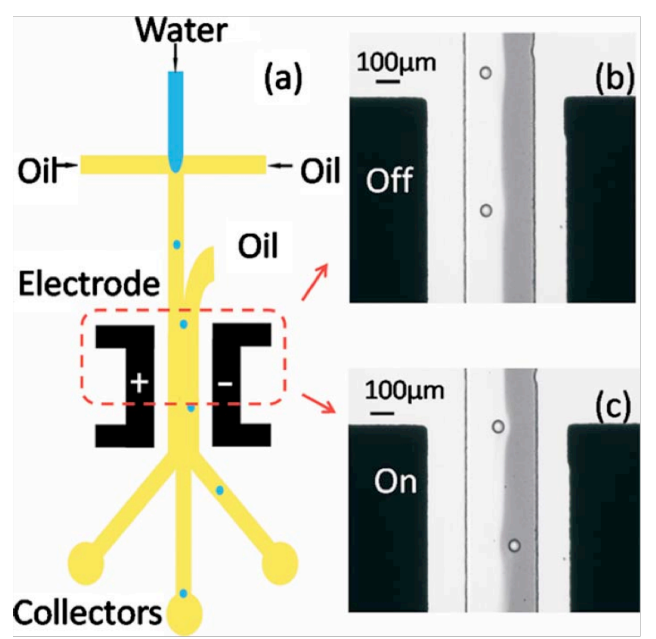

Figure 1.1 (a) Schematic of a microfluidic device employing electrophoresis for cell manipulation. (b) No electric filed applied to the device. (c) Electric field applied to the device. Cell movement from its original stream is observed. Adapted from (Guo et al. 2010).

Radiation forces produced by an optical beam have also been used for cell sorting in a microfluidic flow cytometer, known as optical tweezers. ${ }^{43}$ By producing scattering 
forces and gradient forces, a focused laser beam can trap cells due to the difference in the refractive index between the cell and the surrounding fluid. When the gradient forces are greater than the scattering forces, the cells move towards the beam maxima and become optically trapped (Figure 1.2). ${ }^{44}$ Although an effective approach for the manipulation and sorting of cells, optical tweezers have been shown to produce localize cell heating, and can thus compromise cell viability. ${ }^{45}$

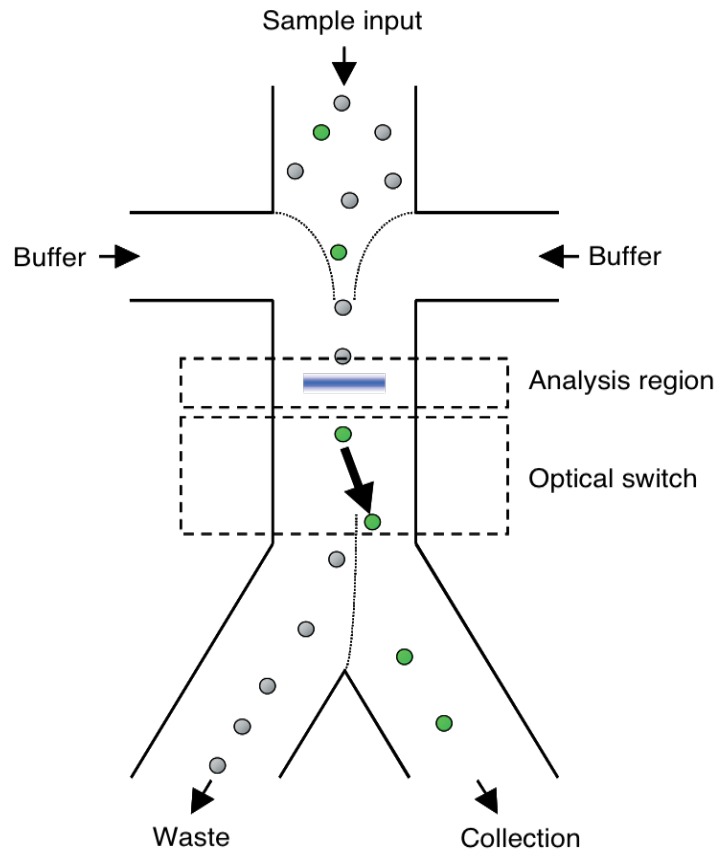

Figure 1.2. Optical switch located in a microfluidic cell sorting junction. Following analysis by fluorescence, target cells are directed by a laser to the desired outlet. The remaining cells flow to the waste chamber. Adapted from (Wang et al., 2005).

While florescent-labeled based cell sorting carries many advantages, the requirement of florescent labeling and serial detection has led to the emergence of alternative techniques, including the use of dielectrophoresis. In systems using dielectrophoresis, cells are 
exposed to an inhomogeneous electric field, which induces the polarization or dipole of a cell. Depending on the conductivity of the cell and the surrounding media, the force either attracts the cell towards the area of high field gradient or repels the cell away from the area of high field gradient. ${ }^{42}$ Using this approach, cells can be sorted based on their size (Figure 1.3) ${ }^{46}$ However, as seen in electrophoretic systems, dielectrophoretic systems also produce Joule heating near the electrodes, which can result to harmful and irreversible effects on the cells of interest. ${ }^{42}$

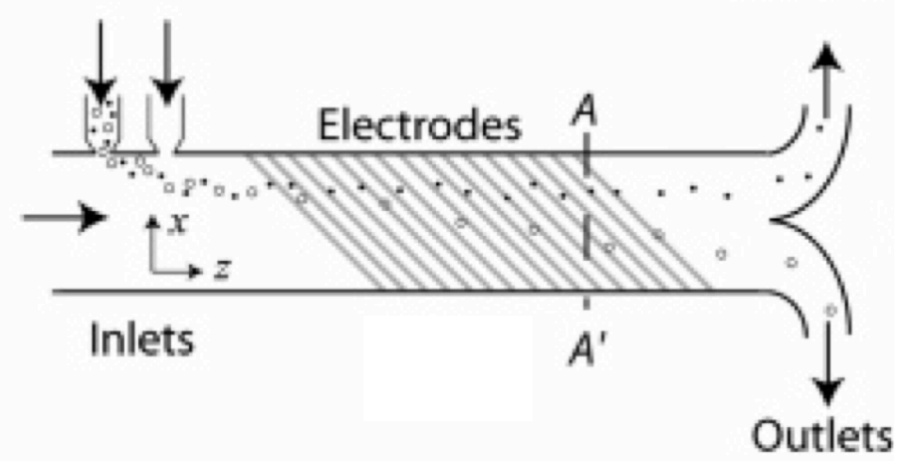

Figure 1.3. Dielectrophoretic force is applied to a blood sample within a microfluidic device. The larger non-platelet-cells and the smaller platelet cells deflect differently when exposed to an inhomogeneous electric field. The different sized cells are sorted downstream. Adapted from (Pommer, Zhang, Chen, Thomson, \& Soh, 2008).

Microfluidic electrophoresis, optical sorting, and dielectrophoresis techniques rely on heat generating forces, and can lead to cell heating and subsequent cellular phenotype modification, or cell death. ${ }^{42,45}$ In response to this challenge, an emerging approach to cell sorting is the use of magnetic force, also referred to as magnetophoresis. Unlike electrophoresis, dielectrophoresis, and optical manipulation, the force generated by the application of a magnetic field, by way of a permanent magnet, does not generate heat 
and therefore, cells are not damaged and can retain their biological activity. ${ }^{47,48}$ In addition, the magnetic field produced by the permanent magnet is orders of magnitude larger than that of micro-magnets or electrodes. As a result, these systems do not require an auxiliary power supply or expensive micro-fabrication ${ }^{49}$ and therefore, the cost and technical training required to employ a magnetophoretic sorting system is greatly reduced.

\subsection{Microfluidic magnetophoretic cell sorting}

The concepts of microfluidics and magnetism have contributed greatly to various fields of research, however, only in recent years have they been combined. Through the integration of magnetic forces into microfluidic systems, we have seen the emergence of novel platforms. ${ }^{50}$

The magnetic force on a particle inside a magnetic field [Eq. 1] depends on the volume of the particle $(V)$, the difference in magnetic susceptibility between the particle $\left(\chi_{p}\right)$ and the surrounding medium $\left(\chi_{m}\right)$, the magnetic flux density $(\boldsymbol{B})$, the magnetic field gradient $(\boldsymbol{\nabla} \boldsymbol{B})$, and the magnetic permeability of free space $\left(\mu_{o}\right)$.

$$
\boldsymbol{F}_{\boldsymbol{m}}=\frac{V\left(\chi_{p}-\chi_{m}\right)}{\mu_{o}}(\boldsymbol{B} \cdot \boldsymbol{\nabla}) \boldsymbol{B}
$$

In microfluidics, materials such as particles or cells can be classified as paramagnetic, or diamagnetic. What determines their categorization is $\Delta \chi$ - the difference in the magnetic susceptibility between the cell or particle $\left(\chi_{p}\right)$, and the surrounding fluid $\left(\chi_{m}\right)$. When $\Delta \chi$ 
measures positive, the material is classified as paramagnetic. Conversely, when $\Delta \chi$ measures negative, the material is classified as diamagnetic.

\subsubsection{Paramagnetic microfluidic systems}

When paramagnetic materials $(\Delta \chi>0)$ are exposed to a magnetic field, the magnetic domains within the material align with the external magnetic field lines and the material experiences an attraction towards the maxima of the magnetic field gradient. Huang et al. developed a paramagnetic microfluidic system for the separation of whole blood by capitalizing on the intrinsic characteristics of nucleated red blood cells (NRBCs). In whole blood, NRBCs are the only cells that contain both a nucleus and haemoglobin. Following a sodium nitrite treatment, haemoglobin is converted into methomoglobin, rendering NRBCs paramagnetic. When paramagnetic NRBCs were passed through a magnetic column, they were attracted towards the maxima of the magnetic field gradient and separated from the original sample. ${ }^{51}$

In microfluidics, paramagnetic materials are also commonly used for cell labelling. Cells are labeled with paramagnetic particles, measuring less than $10 \mathrm{~nm}$ in diameter, and suspended in a non-magnetic fluid. Cell labeling can be achieved either by internal

labeling; introducing paramagnetic nanoparticles into the cell via endocytosis, ${ }^{52,53}$ or by external attaching; attaching the paramagnetic particles to the cell surface. ${ }^{54}$ When labeled-cells within a microfluidic system are exposed to a magnetic field, they are drawn away from the direction of laminar flow and towards a higher magnetic field gradient. ${ }^{17}$ By using internal cell labeling, Pamme et al. achieved the continuous sorting of living 
cells, macrophages and HeLa cells (Figure 1.4). ${ }^{47}$ Although cell sorting can be achieved through the use of paramagnetic materials, the required labeling steps are laborious and time consuming. ${ }^{55}$

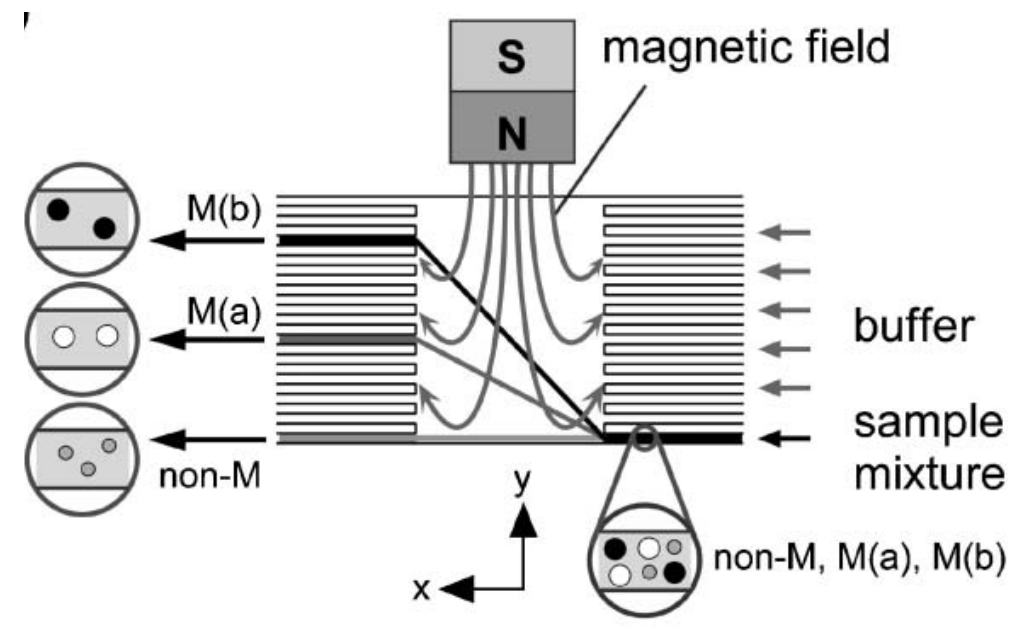

Figure 1.4. Schematic of a magnetophoretic microfluidic device. Sample mixture of magnetic labeled macrophage cells $\left(\mathrm{M}_{\mathrm{a}}\right)$, magnetic labeled HeLa cells $\left(\mathrm{M}_{\mathrm{b}}\right)$, and nonmagnetic particles are introduced together into the device in the $\mathrm{x}$-direction. The sample travels through a separation chamber. A magnetic field is applied in the y-direction. Magnetic labeled cells are deflected from their laminar flow towards the magnetic field gradient. Non-magnetic particles continue in the direction of their laminar flow. Adapted from (Pamme \& Wihelm, 2006).

\subsubsection{Diamagnetic microfluidic systems}

While magnetic forces can be used to manipulate paramagnetic materials inside a microchannel; they can also be used to manipulate non-magnetic, i.e. diamagnetic objects. Diamagnetic materials $(\Delta \chi<0)$, often referred to as non-magnetic, are repelled away from magnetic fields. Most biological materials are weakly diamagnetic, such as proteins, DNA and cells. ${ }^{50}$ If a diamagnetic object is placed in a paramagnetic medium, 
the difference in magnetic susceptibility $(\Delta X)$ is always negative and diamagnetic objects will be repelled away from the magnetic field. As $\chi_{m}$ increases [Eq. 1], and all other variables remain constant, the repelling force will increase. ${ }^{18,56,57}$ An example of a magnetic medium commonly used in microfluidics is ferrofluid. Ferrofluids are a homogeneous liquid phase. They possess permanent magnetization, a strong $\chi_{m}$, and are comprised of three-components. The first component consists of spherical magnetite particles $\left(\mathrm{Fe}_{3} \mathrm{O}_{4}\right) .{ }^{58}$ The average particle diameter measures $10 \mathrm{~nm}$ and is composed of 6200 molecules of $\mathrm{Fe}_{3} \mathrm{O}_{4}$ (Figure 1.5 (a)). These particles can be considered nanomagnets and will experience attractive magnetic forces, as well as Van Der Waals force. To achieve a stable suspension, agglomeration of the particles must be prevented. Therefore, the second ferrofluid component is a surfactant. Through the addition of a surfactant, such as tetramethylammonium hydroxide, the particles can be kept in a colloid state. ${ }^{59}$ The magnetite particles are coated by hydroxide anions, which in turn attract the tetramethylammonium cations. This attraction forms a shell around each magnetite particle and creates repulsion between the particles (Figure 1.5 (b)). ${ }^{60}$ The third and final component is a carrier liquid medium. The choice of carrier, such as oil or aqueous carriers, is dependent upon the application. ${ }^{61}$ The resulting product of all three components is a liquid that possess strong and homogeneous magnetic properties. 


\section{a}

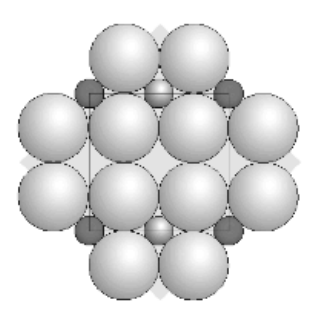

b

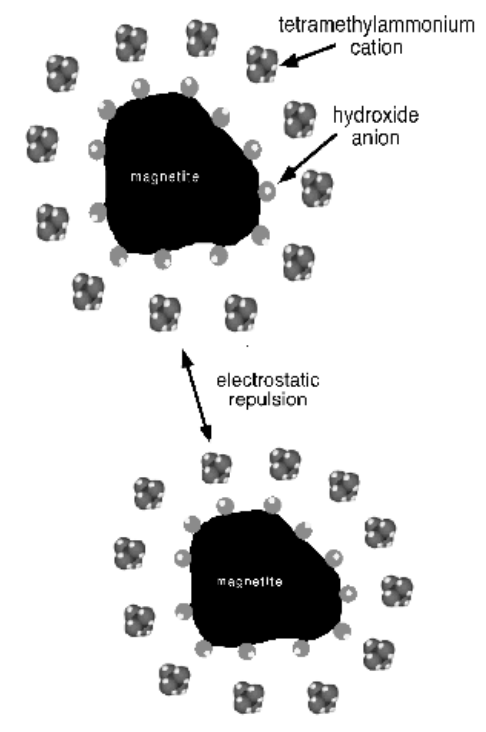

Figure 1.5. Schematics of ferrofluid magnetite particles and surfactants. (a) Molecular structure of magnetite. $\mathrm{Fe}^{+3}$ is represented by circles of two sizes. The smaller circles represent iron in tetrahedral coordination, and the large representing octahedral coordination. (b) Illustration of an aqueous ferrofluid stabilized by a surfactant, tetramethylammonium hydroxide. The surfactant particles adhere to the surface of the magnetitie particles. The magnetite particles experience repulsion from one another and the colloid is stabilized. Adapted from (Berger et al., 1999).

Diamagnetic systems that utilize the properties of ferrofluid can benefit from several advantages over paramagnetic systems. Some of these advantages include the removal of cell-labeling steps, low cost instrumentation, and the system's simplistic design. Zhao, et al. ${ }^{18}$ demonstrated size-based sorting of cells using a diamagnetic system (Figure 1.6). A heterogeneous mixture of cells was suspended in a continuous phase of aqueous ferrofluid. When exposed to a magnetic field, the different sized cells would deflect differently away from their laminar flow and thereby separate from one another. The cells were then sorted into different collection chambers based on their size. ${ }^{24}$ 
(a)

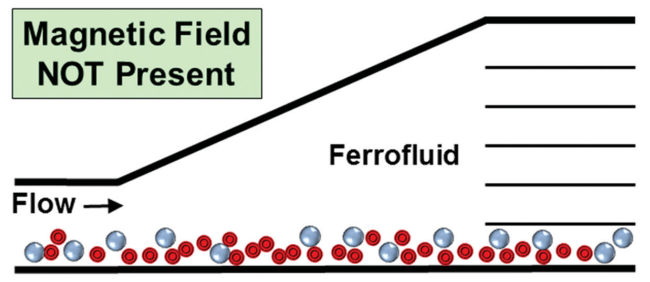

(b)

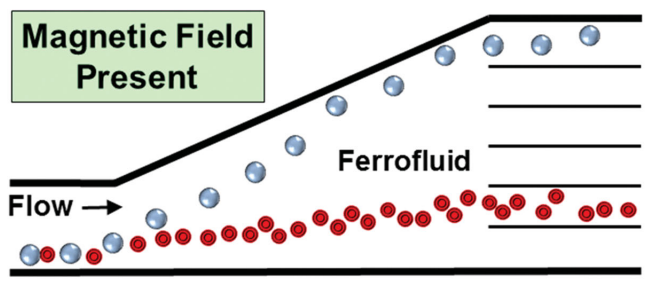

Permanent magnet
- HeLa cell

- Blood cell

Figure 1.6. Schematic representation of a homogeneous sample of cells traveling through a microfluidic device. (a) Cell mixture enters the device and all cells exit the same outlet when no magnet is applied. (b) Cell mixture enters the device. Cells deflect differently when exposed to a magnetic field, and exit through different outlets. Adapted from (Zhao et al., 2016).

Although effective cell sorting is achieved in diamagnetic systems, cells in these systems are directly suspended in potentially harmful magnetic mediums. To overcome the inherent non-biocompatible composition of ferrofluids, many studies have synthesized aqueous ferrofluids that allow for short-term cell viability. ${ }^{25,62}$ However, to render even these ferrofluids biocompatible with mammalian cells, surfactants, $\mathrm{pH}$ value, and the general chemical compatibility of the ferrofluids must be adjusted to accurately reflect cell-specific physiological conditions. ${ }^{24,63}$ With over 200 types of cells in the human body, an effective diamagnetic cell sorting approach with wider applicability is highly desirable. $^{64}$

\subsection{Overview of thesis}

In this thesis, a microfluidic system is introduced for label-free diamagnetic sorting of cell-containing droplets. Empty aqueous droplets, as well as cell-containing droplets are 
generated and suspended in an oil-based ferrofluid. Using a permanent magnet, droplets are sorted based on their cargo-content. Cells are sorted at a high purity and are protected from their harmful surroundings through their encapsulation in the commercially available biocompatible growth medium.

\subsection{Authors contributions}

The work presented in this thesis was initiated by the author and Dr. Scott S. H. Tsai. The microfluidic device was fabricated by the author and Jennifer Kieda. The experimental setup was designed by the author. The fluid phases were prepared by the author. The experiment and data analyses were conducted by the author and Jennifer Kieda. The author, Jennifer Kieda, and Dr. Scott S. H. Tsai all contributed to discussing the results. 


\section{Chapter 2}

\section{Experimental Methods}

\subsection{Chemicals}

In order to generate droplets in a microfluidic device, two liquid phases; the continuous oil phase and the disperse aqueous phase must be prepared. A commercial oil-based ferrofluid (EMG 911, Ferrotec Co., Santa Clara, CA, USA) is used for the continuous phase. The magnetic particle concentration within the ferrofluid is $2 \%$ with particle diameters measuring $10 \mathrm{~nm}$ in size. The continuous phase solution is prepared with a 1:2 ratio mixture of ferrofluid and mineral oil (Sigma-Aldrich, St. Louis, MO, USA), respectively. In addition, 2 v/v\% of Span 80 (Sigma-Aldrich, St. Louis, MO, USA), a commercially produced surfactant, is added to the continuous phase solution to decrease interfacial tension and prevent droplet coalescence. The disperse phase for measurement of droplet deflection is comprised of $100 \mathrm{v} / \mathrm{v} \%$ glycerol (Sigma-Aldrich, St. Louis, MO, USA). The disperse phase for empty droplet and particle-containing droplet sorting is $100 \mathrm{v} / \mathrm{v} \%$ DI H2O. The disperse phase for empty droplet and cell-containing droplet sorting is $100 \mathrm{v} / \mathrm{v} \%$ Roswell Park Memorial Institute cell culture medium (RPMI 1640, Sigma-Aldrich, St. Louis, MO, USA), the recommended cell growth culture media for PC-3 cells. ${ }^{65,66}$.

For all cell viability tests, LIVE/DEAD ${ }^{\circledR}$ viability/cytotoxicity kit (Molecular Probes ${ }^{\mathrm{TM}}$, Eugene, OR, USA) is used. The viability kit is a two-colour assay used to determine the 
viability of cells. The kit consists of ethidium homodimer-1 (Ethd-1) and calcein AM. EthD-1 penetrates damaged cell membranes and binds to nucleic acids, producing a bright red fluorescence. Whereas calcein AM is a cell permeable dye that is converted to calcein by the intracellular esterase present in live cells. The conversion of calcein AM to calcein results in a bright green fluorescence. ${ }^{67}$ The first two test solutions include RPMI 1640, and RPMI 1640 droplets surrounded by EMG 911. The third test solution is EMG 408 ferrofluid (Ferrotec Co., Santa Clara, CA, USA) a commercially available aqueous-based ferrofluid that is commonly used in microfluidic systems and considered biocompatible. $^{68,69}$

\subsection{Droplet contents}

In the experiments involving particles (Figure 10), a suspension of $15 \mu \mathrm{m}$ particles (Sigma-Aldrich, St. Louis, MO, USA) in $100 \mathrm{v} / \mathrm{v} \%$ DI H2O is used as the disperse phase. This is done by centrifuging $3 \mathrm{~mL}$ of the stock particle solution in a Falcon tube for 5 minutes to form a pellet of particles at the bottom of the tube. Next, the aqueous solution is removed, leaving only the particles. The DI H2O is then added to the particles and mixed using a vortex mixer.

PC-3 cells (human prostatic carcinoma cells) are used in all cell-encapsulation experiments. PC-3 cells are cultured in a T-75 cell culture flask. The culture medium includes RPMI with $10 \%$ fetal bovine serum (FBS, Wisent Inc., QC, Canada), and $1 \mathrm{w} / \mathrm{v}$ $\%$ Penicillin/Streptomycin (Wisent Inc., QC, Canada). The culture medium is replaced every three days until $90 \%$ confluency is achieved. In preparation for experiments, the 
cells are passed with trypsin (Wisent Inc., QC, Canada), and then centrifuged at 1,000 rpm for 5 minutes to separate the cells from their original suspension. The cells are then washed with phosphate buffered saline (PBS, MULTICELL, Wisent Inc., QC, Canada) and re-suspended in RPMI 1640.

\subsection{Device fabrication}

The microfluidic device used in all experiments is fabricated using common soft lithography procedures. ${ }^{27}$ The techniques used include designing a microchannel patterned photomask using a computer-aided software (AutoCAD 2017, Autodesk, Inc., San Rafael, CA, USA). The photomask is then printed onto a transparency sheet (CAD/Art Services Inc., Bandon, OR, USA). A silicon wafer (University Wafer, Inc., Boston, MA, USA) is used to fabricate design features. The silicon wafer is spin-coated using SU-8 2050 photoresist (MicroChem, Newton, MA, USA) and is exposed to UV light through the photomask to create the microchannel patterns. Developer solution is then used to wash the wafer and eliminate the unexposed parts of the photoresist, resulting in the base silicon mold.

The base silicon mold is filled using polydimethylsiloxane (PDMS) resin and a curing agent (Sylgard 184, Dow Corning, Midland, MI, USA) at a 10:1 ratio. To allow for the PDMS to cure, it is placed in an oven with a temperature of $70{ }^{\circ} \mathrm{C}$ for 2 hours. The PDMS is then cut around its respective design. One-millimeter diameter biopsy punches (Integra Miltex, Inc., Rietheim-Weilheim, Germany) are used to create the inlets and outlets. A small cut adjacent to the channel wall is made in the PDMS slab to 
accommodate for placing of the magnet. Then, using oxygen plasma treatment, (Harrick Plasma, Ithaca, NY, USA) the PDMS cut-out is bonded to a glass slide and the surfaces of the microchannel gain hydrophilic properties. The bonded cut-out and glass slide are then placed in an oven for 30 minutes to allow optimal adhesion. During this time, the surfaces of the microchannel will regain their natural hydrophobicity.

The design of the microfluidic device includes a flow focusing junction and a sheath flow for the generation of droplets, as shown in Figure 2.1. Dimensions of the main microfluidic channel are $50 \mu \mathrm{m}$ in height, $600 \mu \mathrm{m}$ in width, and $2.35 \mathrm{~cm}$ in length, with an orifice at the flow-focusing junction measuring $30 \mu \mathrm{m}$ in width. A sorting region with four sub-channels is located downstream of the main channel and is used for the sorting and collection of droplets. 


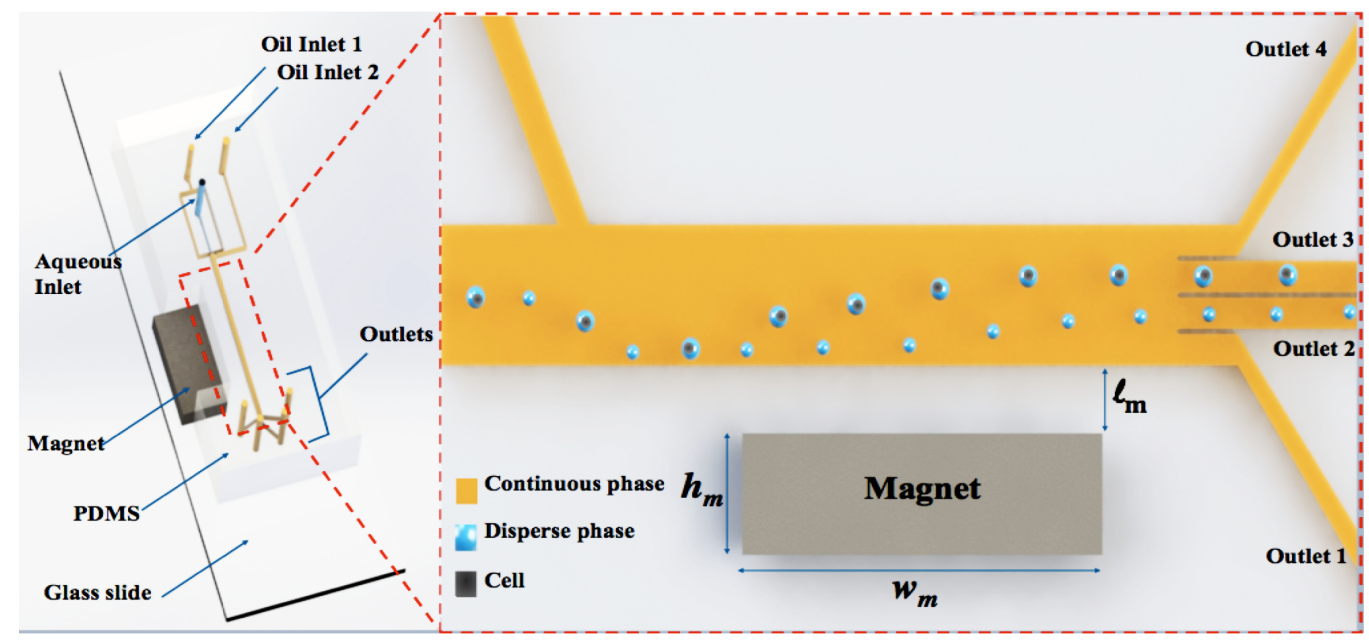

Figure 2.1. Schematic diagram of the microfluidic system with a flow-focusing geometry. Continuous phase consisting of magnetic ferrofluid, mineral oil, and $2 \mathrm{v} / \mathrm{v} \%$ Span 80 is introduced to oil inlet 1 and oil inlet 2, Disperse phase of RPMI 1640 and PC3 cells are introduced to the aqueous inlet. Empty droplets and cell-containing droplets are generated at the flow-focusing junction. The application of a permanent magnet attracts the magnetic continuous phase, while diamagnetically deflecting both empty and cellcontaining droplets. The encapsulation of cells in the droplets results in an increase in droplet diameter. The amount of droplet deflection is positively related to the size of the droplet diameter.

\subsection{Experimental setup}

All experimental imaging of droplets is captured using an inverted microscope (AX10, Carl Zeiss AG, Oberkochen, Germany) and a high-speed camera (Miro M110, Vision Research, Wayne, NJ, USA) that is connected to the microscope. Images and videos were analyzed through the computer-aid software, ImageJ. A neodymium block magnet (NdFeB, B82X0, K. J. Magnetics, Jamison, PA, USA) with a magnetization of 1.05 MA $\mathrm{m}^{-1}$ and dimensions of $1.27 \mathrm{~cm}($ width $) \times 0.32 \mathrm{~cm}$ (height) $\times 2.54 \mathrm{~cm}$ (length) serves as 
an external magnet that is placed adjacent to the microchannel in order to generate a magnetic field.

Droplet generation was established using three constant flow rate syringe pumps (Harvard Instruments, Holliston, MA, USA) providing steady flow rates for the oil carrier phase, known as the continuous-phase, and the aqueous droplet phase, known as the disperse-phase. Two continuous-phase flow rates $\left(Q_{c}\right)$ are analyzed, $Q_{c}=18 \mu \mathrm{L} / \mathrm{min}$ and $Q_{c}=35 \mu \mathrm{L} / \mathrm{min}$. Four trials are run, varying in disperse-phase flow rates $\left(Q_{d}\right)$. For the $Q_{c}$ $=18 \mu \mathrm{L} / \mathrm{min}$ flow rate, the two disperse-phase flow rates that are used include $Q_{d}=1.0$ $\mu \mathrm{L} / \mathrm{min}$ and $Q_{d}=0.3 \mu \mathrm{L} / \mathrm{min}$. For the $Q_{c}=35 \mu \mathrm{L} / \mathrm{min}$ flow rate, the two disperse phase flow rates that are used include $Q_{d}=1.5 \mu \mathrm{L} / \mathrm{min}$ and $Q_{d}=0.5 \mu \mathrm{L} / \mathrm{min}$.

The generation of aqueous droplets is carried out in the PDMS flow-focusing device shown in Figure 7. A magnetic solution, consisting of EMG 911, mineral oil, and span80 , is introduced into oil inlet 1 and oil inlet 2 as the continuous phase. Glycerol is introduced to the system through the aqueous inlet as the disperse phase. Constant flow rate syringe pumps (Harvard Instruments, Holliston, MA, USA) supply flow rates for both solutions. Once the two phases are introduced to the system, the disperse phase forms a thin tip at the flow-focusing junction and it is broken into droplets when shorn by the continuous phase from both sides. This break up is due to Rayleigh-Plateau instability, in which cylindrical jets of a fluid inside another fluid experience instability and subsequent break up into droplets. ${ }^{70}$ Monodispersed glycerol droplets are generated 
in the continuous phase using a jetting regime; a flow breakup in which droplets are formed downstream of the flow-focusing junction through the breakup of a long jet. ${ }^{71}$

All experimental florescence imaging is captured using The ZOE Fluorescent Cell Imager (BIO-RAD, Hercules, CA, USA). As mentioned, the cell viability is determined using a LIVE/DEAD ${ }^{\circledR}$ viability/cytotoxicity kit. The kit consists of ethidium homodimer1 (Ethd-1) and calcein AM. PC-3 cells are added to a solution containing EthD-1 and calcein AM. The cells remain in the solution for 20 minutes at a temperature of $37^{\circ} \mathrm{C}$. Following incubation, 5 million PC-3 cells are added to $600 \mu \mathrm{L}$ samples of each of the three test solutions. In Test 1, cells are added to a solution of $100 \mathrm{v} / \mathrm{v} \%$ RPMI 1640 . The RPMI 1640 cell-containing solution is introduced to our microfluidic system to achieve cell encapsulation and sorting of cell-containing droplets from empty droplets. Following effective sorting of droplets, the cell-containing RPMI 1640 droplets are retrieved from a collection chamber connected to Outlet 2. The cell-containing RPMI 1640 droplets remain suspended in the magnetic continuous phase medium. For Test 2, cells are added to a commercially available water-based magnetite ferrofluid (EMG 408 Ferrotec, Corp., Santa Clara, CA, USA). EMG 408 is selected for this test as previous diamagnetic cell separation studies have demonstrated its biocompatibility with E. coli cells (strain MG1655) and yeast cells (Saccharomyces cerevisiae). ${ }^{66,69}$ Lastly, in the control test, cells are added to a solution of $100 \mathrm{v} \%$ RPMI 1640 . Cells remained within each of the three solutions and a cell sample size of $\mathrm{n}=20$ are analyzed for viability with respect to time. Florescence imaging for each sample is captured at three time intervals; 0 hours, 1 hour, and 2 hours. 


\section{Chapter 3}

\section{Results and Discussions}

\subsection{Diamagnetic droplet deflection}

To achieve manipulation of non-magnetic droplets, we utilize both a hydrodynamic laminar flow and diamagnetism. The application of the external magnetic field introduces magnetic buoyancy force to the system. Glycerol droplets exposed to the buoyancy force are deflected from their laminar flow path (Figure 3.1 (a)) when compared to the absence of a permanent magnet and thus the absence of the buoyancy force (Figure 3.1 (b)). The deflection observed is the result of the difference in the magnetic susceptibility of the ferrofluid medium found in the continuous phase and the glycerol droplets that make up the disperse phase. The magnetic susceptibility of the ferrofluid medium, measuring $\chi_{m} \sim$ $0.11,{ }^{72}$ is much higher than that of the glycerol droplets measuring $\chi_{p} \sim-10^{-8} .{ }^{73}$ As the magnetic nanoparticles within the ferrofluid medium are attracted to the magnet, glycerol droplets are simultaneously deflected from their laminar flow when they encounter the area of the highest magnetic field gradient (Figure 3.1 (a)). The glycerol droplets experience the repelling force $\left[\mathrm{Eq} 11 . .^{56}\right.$ Where $\chi_{p}$ and $\chi_{m}$ are the magnetic susceptibilities of the droplets and the paramagnetic medium, respectively. 

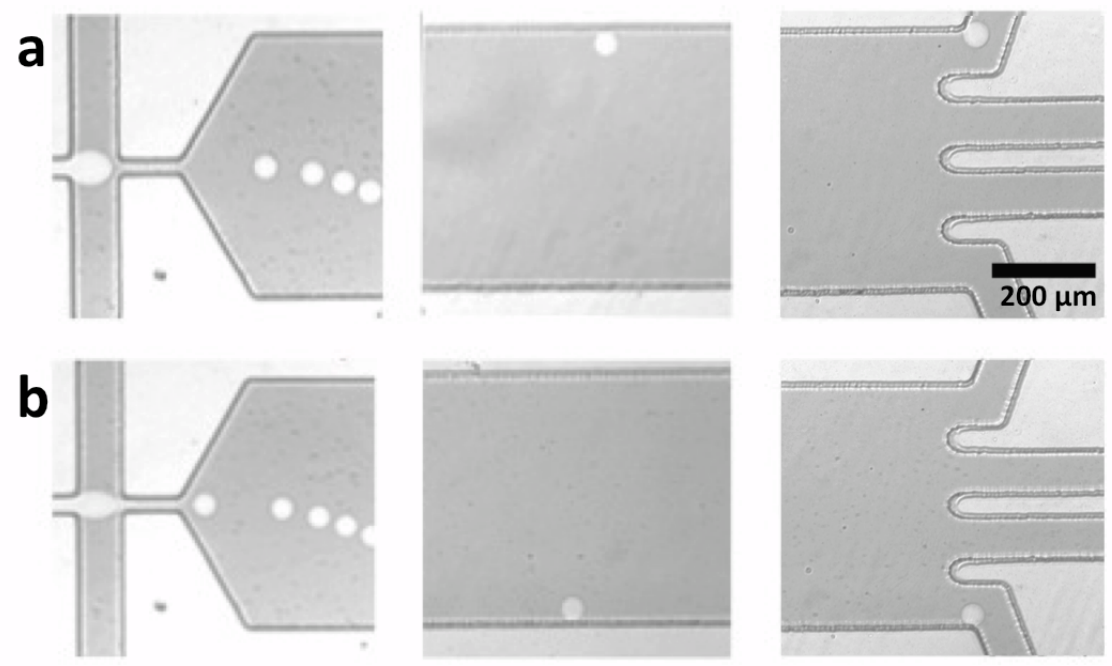

Figure 3.1. Time series images of glycerol droplets captured sequentially downstream the main channel in a continuous phase of ferrofluid. (a) Magnetic field is applied at a magnet distance $\ell_{\mathrm{m}}=1.1 \mathrm{~mm}$ and droplets are sorted into the upper outlet (b) Magnetic field is not applied to the system and droplets are sorted into the lower outlet. Deflection of the glycerol droplets is observed with magnetic field applied.

\subsection{Diamagnetic droplet control}

The deflection of aqueous droplets in a continuous phase of paramagnetic solution has been demonstrated to be proportional to the magnetic field gradient. ${ }^{74,75,76}$ Control of such droplets has been achieved through the use of a permanent magnet. Kim et. al. (2014), showed on-demand routing of aqueous droplets in an oil-based ferrofluid by manipulating magnet positions. In this report, we extend this concept by presenting a method for droplet control by evaluating the effect of the disperse phase flow rate on droplet deflection at a fixed magnet distance $\left(\ell_{m}\right)$. Secondly, we evaluate and exploit the effect of cell-encapsulation on droplet deflection to achieve droplet sorting based on cargo-content. 
To evaluate droplet control at a fixed magnet position, two pairs of trails are conducted. In each trial pair, a fixed continuous phase flow rate, $Q_{c}$, is maintained and only the disperse phase flow rate, $Q_{d}$, is changed. The change in droplet deflection (where $\mathrm{n}=20$ ) is measured as it relates to the change in the disperse phase flow rate. The first pair of trials are conducted at $Q_{c}=35 \mu \mathrm{L} / \mathrm{min}$ with a high and low $Q_{d}$ of $1.5 \mu \mathrm{L} / \mathrm{min}$ and 0.5 $\mu \mathrm{L} / \mathrm{min}$, respectively. Figure 3.2 shows that when the ratio of $Q_{d}$ to $Q_{c}$ is increased by increasing the disperse flow rate, the diameter of the droplets is increased. Furthermore, we observe an increase in droplet deflection with the increase in droplet diameter. To ensure reproducibility of the results, a second pair of trials is conducted at $Q_{c}=18$ $\mu \mathrm{L} / \mathrm{min}$ with a high and low $Q_{d}$ of $1.0 \mu \mathrm{L} / \mathrm{min}$ and $0.3 \mu \mathrm{L} / \mathrm{min}$, respectively. The results for both the first and second pairs of trials are consistent across the four magnetic distances, $\ell_{m}$. In accordance with pervious studies, it is observed that droplet deflection increases as $\ell_{m}$ decreases (Figure 3.2). ${ }^{74}$ Therefore, by simply adjusting the flow rate of the dispersed phase, the droplet diameter is increased or decreased, and thus the degree of droplet deflection is precisely controlled (Figure 3.2). 


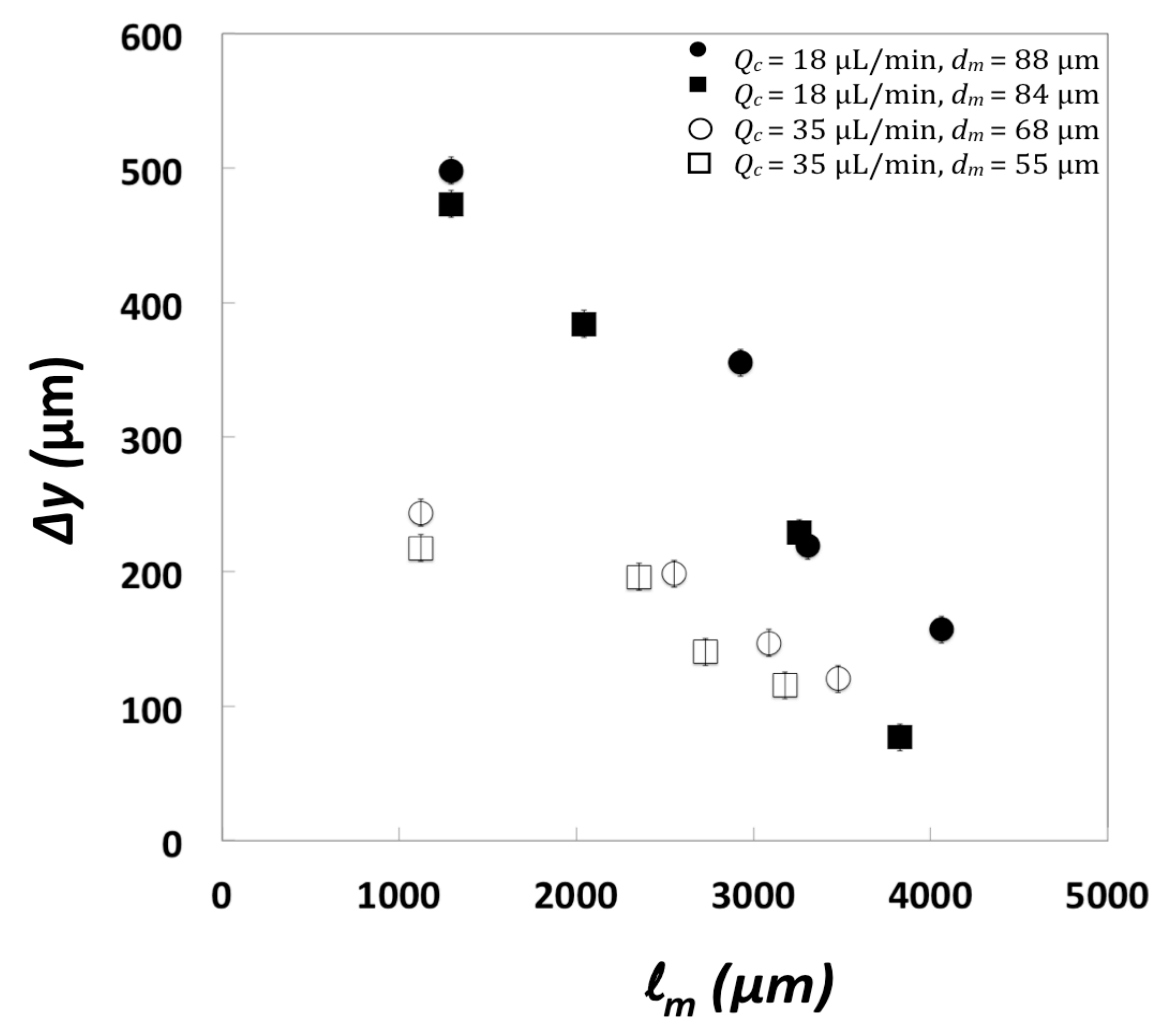

Figure 3.2. A plot of the deflection distances of droplets with respect to four consecutive distances of the magnet $\left(\ell_{m}\right)$ from the channel wall. The deflected droplet distances are measured at two continuous-phase flow rates $\left(Q_{c}=18 \mu \mathrm{L} / \mathrm{min}\right.$ represented by the filled data points and $Q_{c}=35 \mu \mathrm{L} / \mathrm{min}$ represented by the empty data points). For each continuous-phase flow rate, droplet deflection distance is measured for two trials of differing disperse-phase flow rates in $\mu \mathrm{L} / \mathrm{min}$ (disperse phase high and disperse phase low). The droplet deflection distance $(\Delta y)$ represents the difference between the controlled droplet distance from the channel wall (without a magnetic field applied) from the experimental droplet distance from the channel wall (with magnetic field applied). Droplet deflection distances generally decreased with increase in magnet distance, and with decrease in droplet diameter $\left(d_{m}\right)$ measured in $\mu \mathrm{m}$. Error bars indicate the distribution of droplet deflection. Scale bar: $100 \mu \mathrm{m}$. An analysis of variance showed that the effect of $\ell_{m}$ on $\Delta y$ was significant, $\mathrm{F}(3,4)=0.56, \mathrm{P}=0.05$. 


\subsection{Sorting based on droplet contents}

In a previous study, a change in droplet diameter was seen following cell encapsulation. ${ }^{77}$ Using these findings, as well as our observation of size-based droplet control, we evaluate the effect of cell encapsulation on droplet deflection and subsequent droplet sorting. The device is first calibrated using spherical polystyrene microparticles with diameters of $15 \mu \mathrm{m}$ and a similar total volume (volume of $2000 \mu \mathrm{m}^{3}$ ) 78 to PC-3 cancer cells $\left(1800 \mu \mathrm{m}^{3}\right)$. The polystyrene microparticles are introduced to the disperse phase. In order to produce size distinction between empty droplets and particle-containing droplets, the optimal flow rates are found to be $Q_{d}=5 \mu \mathrm{L} / \mathrm{min}$ and $Q_{c}=35 \mu \mathrm{L} / \mathrm{min}$. Under this flow condition, the diameter of empty droplets measure $12 \mu \mathrm{m}$. The encapsulation of the microparticles expands the particle-containing droplet diameter to $23 \mu \mathrm{m}$. The $11 \mu \mathrm{m}$ size difference is utilized for subsequent size-based sorting using diamagnetic force. Figure 6 summarizes the device performance for microparticle separation. Figure 3.3(a)(c) shows that with no magnet applied to the system 93\% of empty droplets, measuring 12 um in diameter, and $100 \%$ of particle containing droplets, measuring $23 \mu \mathrm{m}$ in diameter, follow their original flow direction inside the microchannel and are sorted into outlet 1 . The difference in droplet diameter between empty droplets and particle-containing droplets is then exploited for droplet content-based sorting (Figure 3.3(b)(d)). A magnet is applied at $1_{m}=1.1 \mathrm{~mm}$. The small empty droplets are slightly deflected from their original path with 99\% traveling through outlet 2 (Figure 3.3(d)). The droplets containing a particle, whose diameters are $11 \mu \mathrm{m}$ larger than that of the empty droplets, are deflected from their original path toward the upper wall of the main channel. Of the particle-containing 
droplets, $90 \%$ are sorted from the empty droplets and travel through Outlet 3 (Figure $3.3(d))$.
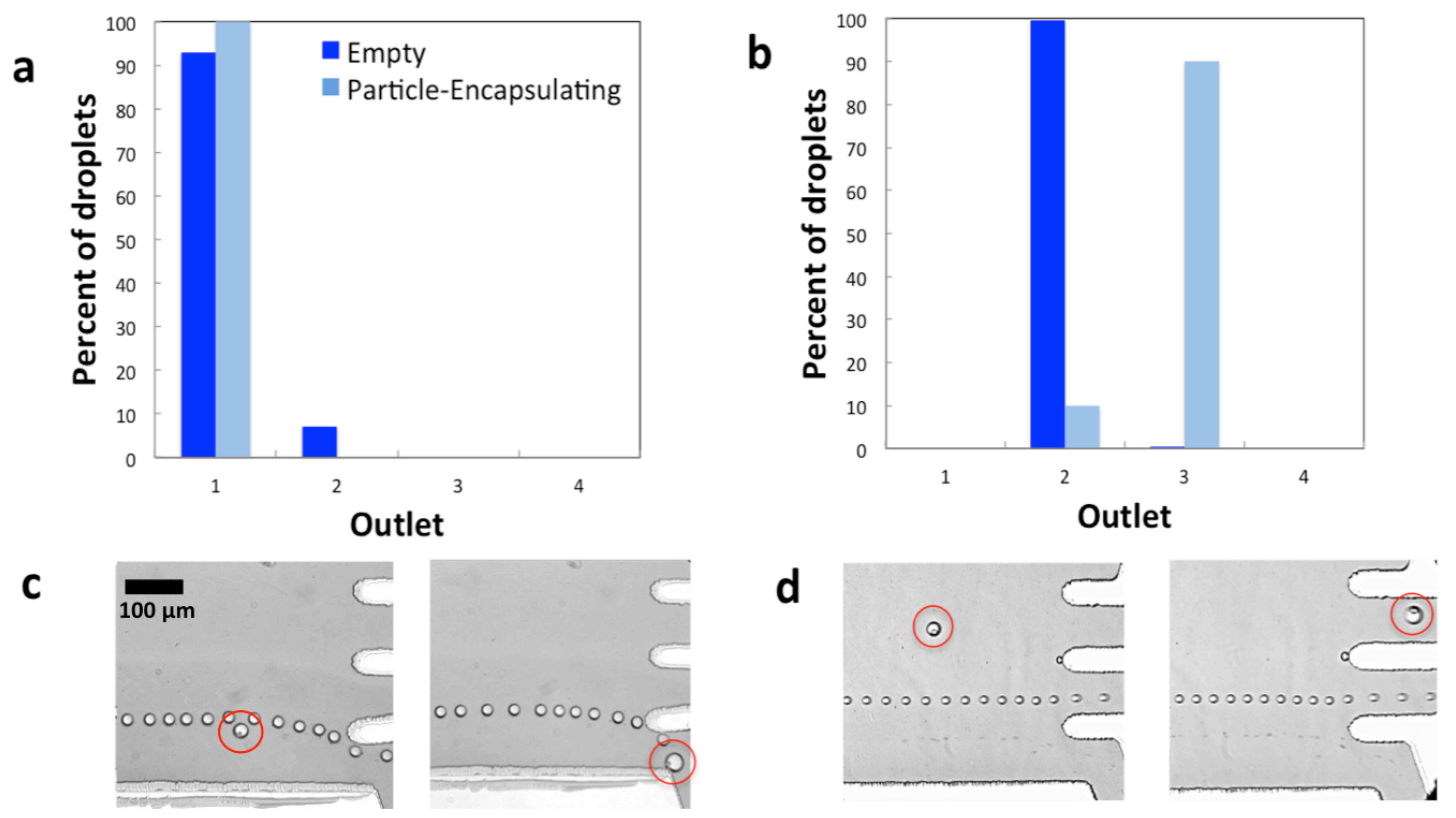

Figure 3.3. The application of a magnetic field on the effect of sorting particlecontaining droplets and empty droplets into downstream outlets. (a) Percent of particlecontaining droplets and empty droplets that exit through each outlet when no magnet is applied. (b) Percent of particle-containing droplets and empty droplets that exit through each outlet when a permanent magnet is applied at $1_{m}=1.1 \mathrm{~mm}$. (c) Image series of particle-containing droplets captured downstream of main channel in a continuous phase of ferrofluid. Magnetic field is not applied to the system. Particle-containing droplets and empty droplets sort into outlet 1 (d) Magnetic field is applied at a magnet distance $1_{m}=$ $1.1 \mathrm{~mm}$. Sorting of particle-containing droplets and empty droplets into different outlets is observed with magnetic field applied. Scale bar: $100 \mu \mathrm{m}$. 


\subsection{Cell-containing droplets}

Next, we test the device is tested using a human prostatic carcinoma cell line, PC-3 cells, in place of polystyrene particles. The optimal laboratory environment for PC-3 cells is incubation in RPMI $1640 .^{65,79}$ In order to optimize cell viability, the disperse phase is comprised of RPMI 1640. Figure 3.4(a) shows a distribution analysis of empty droplets and cell-containing droplets when no magnet is applied to the system. It is observed that $100 \%$ of empty droplets and $99 \%$ of cell-containing droplets are sorted into outlet 1. Separation of empty droplets and cell-containing droplets is successfully achieved with the application of a magnetic field. Figure 3.4(b) shows a distribution analysis of empty droplets and cell-containing droplets when a magnet is applied to the system at $1_{m}=1.1$ $\mathrm{mm}$. Here, when the magnet is applied, $98.5 \%$ of empty droplets are sorted into outlet 1 and $84 \%$ of PC-3 cells are sorted into Outlet 2 at a sorting throughput of $2.6 \times 10^{4}$ cells $/ \mathrm{h}$ (Figure 3.4(a)(b)).

The difference in deflection observed between empty droplets and cell-containing droplets is consistent with findings from previous work on cell-encapsulation, as well as the previously mentioned repelling force equation Ch. 1. [Eq. 1]. Jing et al. (2014) demonstrated a change in droplet diameter when comparing empty droplets and cellcontaining droplets. In using these findings, we established a difference in droplet diameter of $11 \mu \mathrm{m}$ between cell-containing droplets and empty droplets in our system. Based on the repelling force equation [Eq. 1], we can expect a change in droplet deflection when comparing empty droplets and cell-containing droplets. The repelling force equation shows that as the droplet volume changes the repelling force experienced 
by the droplet also changes. Therefore, our observation of the smaller empty droplets deflecting differently than the larger cell-containing droplets is consistent with both the literature and guiding physical principles.

Having demonstrated sorting of empty droplets from cell-containing droplets at a high purity, our system provides a platform for increasing the efficiency of single-cell assays. Droplet-based single-cell assays such as cell secreted molecule screening, ${ }^{80}$ or applications in polymerase chain reaction $(\mathrm{PCR})^{81}$ rely on cell-encapsulation for downstream readouts. The encapsulation of cells in such systems follows Poisson statistics, which can result in a large population of empty droplets and limits the efficiency of these assays. ${ }^{82}$ Through diamagnetic separation of single cell-encapsulated droplets from empty droplets, our platform can address challenges with encapsulation efficiency by providing cell-containing droplets at a purity of $84 \%$. 
a

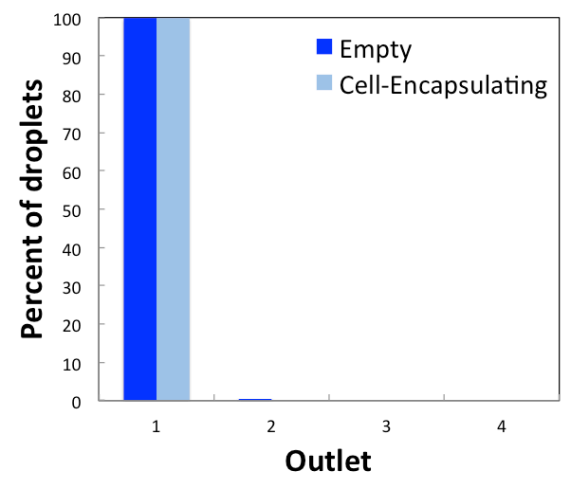

C

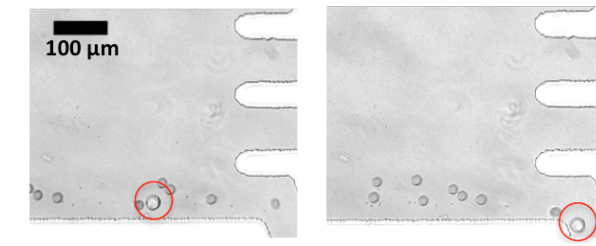

b

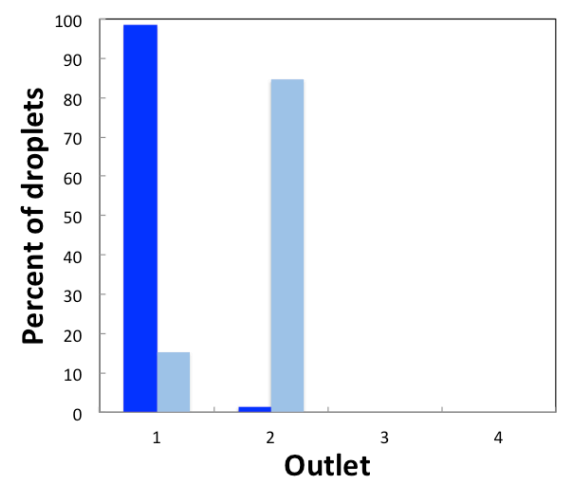

d

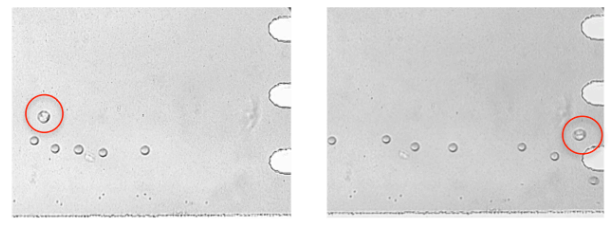

Figure 3.4. The application of a magnetic field on the effect of sorting cell-containing droplets and empty droplets into downstream outlets. (a) Percent of cell-containing droplets and empty droplets that exit through each outlet when no magnet is applied. (b) Percent of cell-containing droplets and empty droplets that exit through each outlet when a permanent magnet is applied at $1_{m}=1.1 \mathrm{~mm}$. Sorting of cell-containing droplets and empty droplets into different outlets is observed with magnetic field applied. (c) Image series of cell-containing droplets captured downstream of main channel in a continuous phase of ferrofluid. Magnetic field is not applied to the system. cell-containing droplets and empty droplets sort into outlet 1 (d) Magnetic field is applied at a magnet distance $1_{m}$ $=1.1 \mathrm{~mm}$. Sorting of cell-containing droplets and empty droplets into different outlets is observed with magnetic field applied. Scale bar: $100 \mu \mathrm{m}$.

\subsection{Single cell fluorescence-based and direct-count assay}

The viability of cells encapsulated in droplets is determined using an LIVE/DEAD ${ }^{\circledR}$ viability/cytotoxicity kit. Following exposure to EthD-1 and calcein AM, cells are added to one of three solutions, Test 1 , Test 2 , and Control. In Test 1 , cells are added to a solution of $100 \mathrm{v} / \mathrm{v} \%$ RPMI 1640, the recommended cell growth culture media for PC-3 
cells. $^{65,66}$ The RPMI 1640 cell-containing solution is introduced to our microfluidic system to achieve cell encapsulation and sorting of cell-containing droplets from empty droplets. Following effective sorting of droplets, the cell-containing RPMI 1640 droplets are retrieved from a collection chamber connected to Outlet 2. The cell-containing RPMI 1640 droplets remain suspended in the magnetic continuous phase medium (Figure 3.5(c)). For Test 2, cells are added to a commercially available water-based magnetite ferrofluid (EMG 408 Ferrotec, Corp., Santa Clara, CA, USA). EMG 408 is selected for this test as previous diamagnetic cell separation studies have demonstrated its biocompatibility with E. coli cells (strain MG1655) and yeast cells (Saccharomyces cerevisiae). ${ }^{69,83}$ Lastly, in the control test, cells are added to a solution of $100 \mathrm{v} \%$ RPMI 1640. Cells remained within each of the three solutions and are analyzed for viability with respect to time. Cell viability is analyzed at 0 hours, 30 minutes, 1 hour, and 2 hours by fluorescence microscopy with a sample size of $n=20$. The percent of viable cells at each time interval is reported in Figure 3.5(a)(b). The results show 100\% viability for the control cells, and $90 \%$ viability for the cells that have been retrieved from our system (RPMI droplets), after 2 hours. Although EMG 408 water-based magnetite ferrofluid has previously been shown as biocompatible with non-mammalian cells such as E. coli and S. cerevisiae, our results show 0\% cell viability when PC-3 cells are incubated in EMG 408 at all time intervals. 

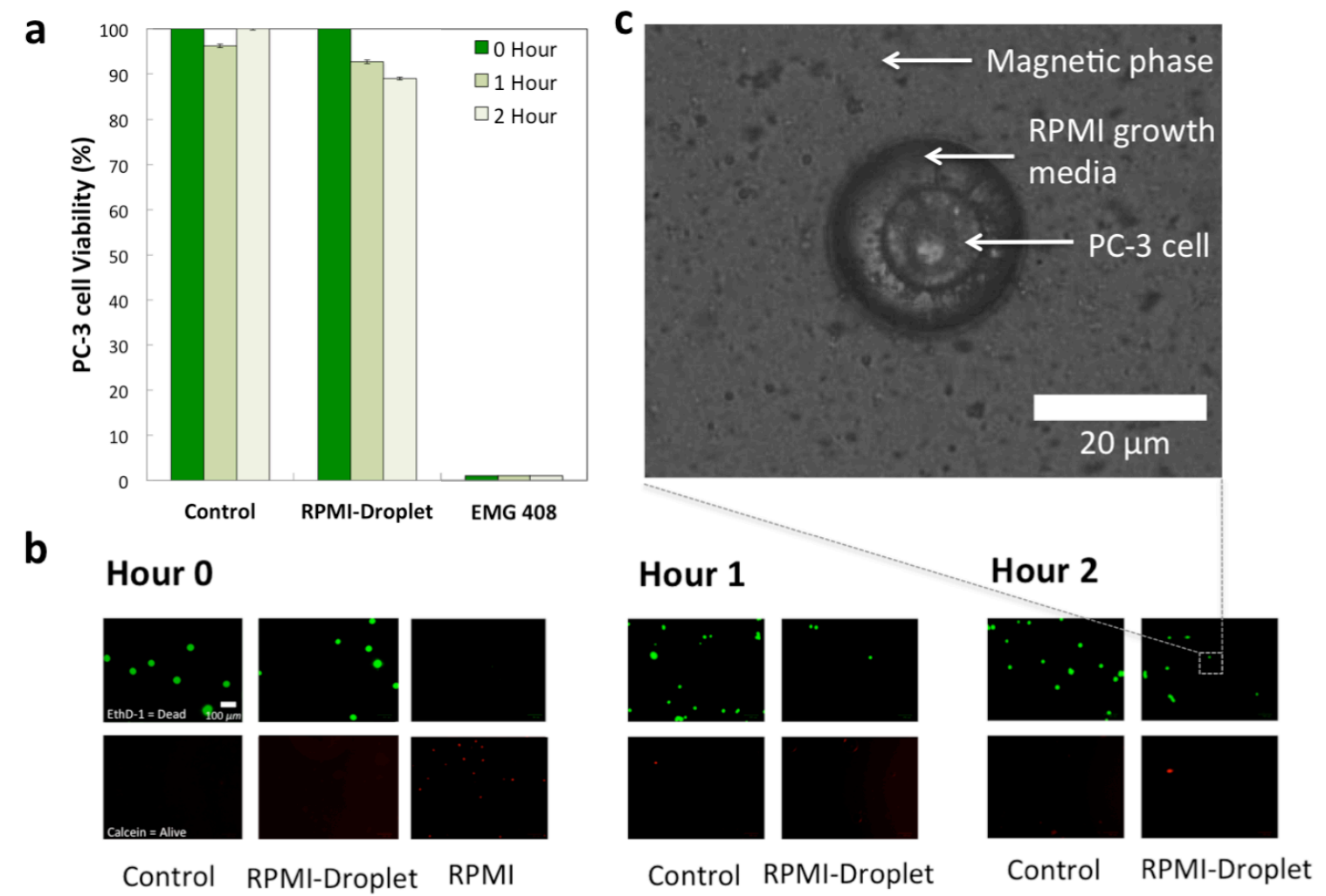

Figure 3.5. (a) The viability of PC-3 cells in different media is compared over time. Cells are incubated in RPMI as the control trial, and the EMG 408 ferrofluid as the EMG 408 trial. In the RPMI droplet trial, cell-containing RPMI droplets surrounded by oil-based ferrofluid are removed from the system and the encapsulated cells are analyzed for viability. (b) Cell viability was determined by adding Calcein AM and EthD-1 to the cell suspension and conducting a fluorescence viability assay. Viability was assessed at 0 hour, 1 hour, and 2 hour marks. The non-viable cells are imaged in red and the viable cells are imaged in green. Viability of PC-3 cells in control RPMI media and the RPMI droplets in oil-based ferrofluid is observed up to 2 hours. EMG 408 shows poor biocompatibility for PC-3 cells, resulting in non-viable cells. (c) Cell-containing droplet surrounded by oil-based ferrofluid that has been removed from the system for assessment of viability. Error bars represent one standard deviation from two different viability tests.

The $90 \%$ viability for the cells encapsulated by droplets suggests that the encapsulating droplet is an effective vehicle to protect cells from their surrounding paramagnetic 
medium. The protective layer that is provided to the cell by way of droplet encapsulation removes the need for the synthesis of biocompatible ferrofluids commonly found in diamagnetic cell sorting systems. ${ }^{83,84}$ Additionally, the encapsulated cells remained viable across all time intervals of our viability tests. Therefore, the cell-containing droplets generated by our system can be considered suitable for subsequent single-cell analysis. 


\section{Chapter 4}

\section{Concluding Remarks}

\subsection{Summary}

In this thesis, we have presented a biocompatible approach for precise control of cellcontaining droplets using diamagnetism. This approach allows for the isolation and sorting of cells, and through the encapsulation of cells in biocompatible droplets, it removes laborious cell-labeling steps common to existing cell sorting techniques, while protecting cells from potentially harmful surroundings.

While the current magnetophoretic approaches to single-cell isolation are robust, the challenge still lies in their need to label cells with magnetic tags, or to synthesize cellspecific biocompatible ferrofluids. We have addressed these concerns in two key areas: diagmagnetically-controlling droplets based on their cargo, and encapsulating cells in biocompatible droplets to protect cells from surrounding ferrofluids. In particular, developments in this thesis cover:

- The manipulation of droplet size through the single step of adjusting the disperse phase flow rate.

- The sorting of droplets based on cargo-content, thus effectively sorting cell-containing droplets from empty droplets.

- The protection of cells through their encapsulation in cell-specific commercially available growth culture medium. 
These particular advancements reveal the potential of our system to increase the efficacy and sensitivity of single-cell assays. The diamagnetic separation of cell-encapsulated droplets from empty droplets provides a platform to reduce the population of empty droplets commonly found in single-cell analysis platforms. Additionally, the magnetic continuous phase used in the system, and magnetic force applied to the system showed no adverse effect on the viability of the cells, thus providing viable encapsulated-cells for analysis without the use of harmful forces. Combined with single-cell assays such as applications in PCR or cell secreted molecule screening, our system can provide the isolation of viable cells at a high purity for subsequent downstream single-cell analysis.

\subsection{Limitations}

Future refinements of this approach are envisioned to extend this system's practicality. First, the system is currently limited to cells measuring $10 \mu \mathrm{m}-80 \mu \mathrm{m}$ in diameter. In order to accommodate cells or biomaterials of diameters measuring $<10 \mu \mathrm{m}$, the system must be scaled down. Second, the throughput of the device is limited by the orifice size. To achieve increased efficiency, the device dimensions must be adjusted to accommodate an increase in the orifice size. With such improvements, this system can provide a costeffective and user-friendly platform for deepening the understanding of the progression and treatment of diseases. 


\subsection{Future directions}

Future applications will involve encapsulating various cell-lines in droplets of their corresponding growth medium and measuring the device's efficacy. Upon gathering consistent results for multiple cell lines, the separation of a heterogeneous cell sample will be tested. If effective, this platform could provide a cell-sorting approach compatible with any chosen mammalian cell-line. Additionally, the compartmentalization provided by cell-encapsulated droplets, allows for the containment of all cell products for subsequent analysis. By integrating a downstream analysis system to our platform, such as PCR amplification and DNA sequencing, single-cell genomes could be analyzed for applications such as disease prognosis and treatment strategies. Thus, producing an accessible multi-step chip encompassing label-free isolation, sorting, and analysis of single cells. 


\section{Bibliography}

${ }^{1}$ D. Rissin, K. Cheuk, T. Campbell, S. Howes, D. Fournier, L. Song, T. Piech, P. Patel, L. Chang, A. Rivnak and E. Ferrell, Nature Biotechnology, 2010, 28, 595-600.

${ }^{2}$ A. Ståhlberg and B. Martin, 2010, Methods, 50, 282-288.

${ }^{3}$ D. Fairbairn, O. Peggy and K. O'Neill, 1995, Mutation Research/Reviews in Genetic Toxicology 339, 37-59.

${ }^{4}$ P. Chattopadhyay, T. Gierahn, M. Roederer and J. Love, 2014, Nature Immunology, 15, $128-135$.

${ }^{5}$ M. Rantalainen, 2017, Briefings in Functional Genomics, 17, 273-282.

${ }^{6}$ K. Pantel and C. Alix-Panabieres, 2010, Trends in Molecular Medicine, 16, 398-406.

${ }^{7}$ M. Khan, A. Kirkwood, T. Tsigani, J. Garcia-Hernandez, J. Hartley, M. Caplin, and T. Meyer, 2013, Journal of Clinical Oncology, 31, 365-372.

${ }^{8}$ M. Cristofanilli, D. Hayes, G. Budd, M. Ellis, A. Stopeck, J. Reuben, G. Doyle, J. Matera, W. Allard, M. Miller and H. Fritsche, 2005, Journal of Clinical Oncology 23, $1420-1430$.

${ }^{9}$ S. Cohen, C. Punt, N. Iannotti, B. Saidman, K. Sabbath, N. Gabrail, J. Picus

M. Morse, E. Mitchell, M. Miller and G. Doyle, 2008, Clinical Oncology, 26, 3213-3221.

${ }^{10}$ L. Lohr, V. Adalsteinsson, K. Cibulskis, A. Choudhury, M. Rosenberg, P. CruzGordillo, J. Francis, C. Zhang, A. Shalek, R. Satija and J. Trombetta, 2014, Nature Biotechnology, 32, 479-484.

${ }^{11}$ A. El Gammal, M. Brüchmann, J. Zustin, H. Isbarn, O. Hellwinkel, J. Köllermann, G. Sauter, R. Simon, W. Wilczak, J. Schwarz and C. Bokemeyer, 2010, Clinical Cancer Research, 16, 56-64. 
${ }^{12}$ M. Rebucci, and C. Michiels, 2013, Biochemical Pharmacology, 85, 1219-1226.

${ }^{13}$ Y . Wang, J. Waters, M. Leung, A. Unruh, W. Roh, X. Shi, K. Chen, P. Scheet, S.

Vattathil, H. Liang and A. Multani, 2014, Nature, 512, 155-160.

${ }^{14}$ T. Wilson, J. Fridlyand, Y. Yan, E. Penuel, L. Burton, E. Chan E, J. Peng, E. Lin, Y.

Wang, J. Sosman and A. Ribas, 2012, Nature, 487, 505-509.

${ }^{15}$ P.B. Noble and J.H. Cutts, 1967, The Canadian Veterinary Journal, 8, 110- 111.

${ }^{16}$ C. Alix-Panabières, J.P. Vendrell, O. Pellé, X. Rebillard, S. Riethdorf, V. Müller, M.

Fabbro and K. Pantel, 2007, Clinical Chemistry, 53, 537-539.

${ }^{17}$ G. Vona, A. Sabile, M. Louha, and V. Sitruk, 2000, The American Journal of

Pathology 156, 57-63.

${ }^{18}$ J. Autebert, B. Coudert, F.C. Bidard, J.T. Pierga, S. Descroix, L. Malaquin, and J.L

Viovy, 2012, Methods, 57, 297-307.

${ }^{19}$ P.J. Crosland-Taylor, 1953, Nature, 171, 37-38

${ }^{20}$ M.J. Fulwyler, 1965, Science, 150, 910-911.

${ }^{21}$ I.V. Shields, C.D. Reyes and G.P López, 2015, Lab on a Chip, 15, 1230-1249.

${ }^{22}$ D.R. Gossett, W.M. Weaver, A.J. Mach, S.C. Hur, H.T. Tse, W. Lee, H. Amini and D.

Di Carlo, 2010, Analytical and Bioanalytical Chemistry, 397, 3249-3267.

${ }^{23}$ D. B. Weibel and G. M. Whitesides, 2006, Current. Opinion Chemical Biology, 10, $584-591$.

${ }^{24}$ D.J. Beebe, G.A Mensing, and G.M Walker, 2002, Annual Review of Biomedical Engineering, 4, 261-286.

${ }^{25}$ E.K. Sackmann, A.L. Fulton, and D.J. Beebe, 2014, Nature, 507, 181-189.

${ }^{26}$ G.M. Whitesides, 2006, Nature, 442, 368-373. 
${ }^{27}$ Y. Xia and G. M. Whitesides, 1998, Annual Review Material Science, 28, 153-184.

${ }^{28}$ D.B. Weibel, W.R. DiLuzio, G.M. Whitesides, 2007, Nature Reviews Microbiology, 5, 209-218.

${ }^{29}$ M.E. Piyasena, and S.W. Graves, 2014, Lab on a Chip, 14, 1044-1059.

${ }^{30}$ E.A. Jamil, P.K. Sorger, and K.F. Jensen, 2006, Nature, 442, 403-411.

${ }^{31}$ S.Y. Teh, R. Lin, L.H. Hung, and A.P, 2008, Lee, Lab on a Chip, 8, 198-220.

${ }^{32}$ C.D. Chin, V. Linder, S.K Sia, 2007, Lab on a Chip, 7, 41-57.

${ }^{33}$ T.M. Squires and S.R. Quake, 2005, Reviews of Modern Physics, 77, 977-1026.

${ }^{34}$ R.B. Bird, W.E. Stewart and E.N. Lightfoot, 2001, Transport Phenomena.

${ }^{35}$ J. Atencia and D.J. Beebe, 2004, Nature, 28, 648-655.

${ }^{36}$ T.M. Squires and S.R. Quake, 2005, Reviews of Modern Physics, 77, 977-1026.

${ }^{37}$ P. Garstecki, M.J. Fuerstman, H.A. Stone HA and G.M. Whitesides, 2006, Lab on a Chip, 6, 437-446.

${ }^{38}$ J. El-Ali, P. K. Sorger and K. F. Jensen, 2006, Nature, 442, 403-411.

${ }^{39}$ J. Krüger, K. Singh K, A. O'Neill, C. Jackson, A. Morrison and P. O'Brien, 2002, Journal of Micromechanics and Microengineering, 12, 486-494.

${ }^{40}$ J. Voldman, 2006, Annual Review Biomedical Engineering, 8, 425-454.

${ }^{41}$ F. Guo, X.H. Ji, K. Liu, R.X. He, L.B. Zhao, Z.X. Guo, W. Liu, S.S. Guo and X.Z. Zhao, 2010, Applied Physics Letters, 96, 1-3.

${ }^{42}$ A.A. Bhagat, H. Bow, H.W. Hou, S.J. Tan, J. Han, C.T. Lim CT, 2010, Medical \& Biological Engineering \& Computing, 48, 999-1014.

${ }^{43}$ M.M. Wang, E. Tu, D.E. Raymond, J.M. Yang, H. Zhang, N. Hagen, B. Dees, E.M. ${ }^{44}$ X. Wang, S. Chen, M. Kong, Z. Wang, K. D. Costa, R. A. Li and D. Sun, 2011, Lab 
on a Chip, 11, 3656-3662.

${ }^{45}$ Y. Liu, G.J. Sonek, M.W. Berns and B.J. Tromberg, 1996, Biophysical Journal, 71, 2158-2167.

${ }^{46}$ Pommer MS, Zhang Y, Keerthi N, Chen D, Thomson JA, Meinhart CD, Soh HT. 2008, Electrophoresis, 6, 1213-1218.

${ }^{47}$ N. Pamme and C. Wilhelm, 2006, Lab on a Chip, 6, 974-980.

${ }^{48}$ W. Zhao, R. Cheng, J.R. Miller and L. Mao, 2016, Advanced Functional Materials, 26, 3916-3932.

${ }^{49}$ T. Zhu, D.J. Lichlyter, M.A. Haidekker and L. Mao, 2011, Microfluidics and

Nanofluidics, 10, 1233-1245.

${ }^{50}$ N. Pamme, 2006, Lab on a Chip, 6, 24-38.

${ }^{51}$ R. Huang, T.A. Barber, M.A. Schmidt, R.G. Tompkins, M. Toner, D.W. Bianchi, R. Kapur, W.L. Flejter, 2008, Prenatal Diagnosis 28, 892-9.

${ }^{52}$ C. Wilhelm, F. Gazeau, J. Roger, J.N. Pons, J.C. Bacri, 2002, Langmuir, 18, 81488155.

${ }^{53}$ C. Billotey, C. Wilhelm, M. Devaud, J. C. Bacri, J. Bittoun and F. Gazeau, 2003, Magn. Reson. Med., 49, 646-654.

${ }^{54}$ A. Ito, M. Shinkai, H. Honda and T. Kobayashi, 2005, Journal of Bioscience and Bioengineering, 100, 1-11.

${ }^{55}$ B.D.Plouffe, S.K. Murthy and L.H. Lewis. 2014, Reports on Progress in Physics, 78, $1-38$. 
${ }^{56}$ A. Winkleman, K.L. Gudiksen, D. Ryan, G.M. Whitesides, D. Greenfield and M. Prentiss. 2004, Applied Physics Letters, 85, 2411-2413.

${ }^{57}$ M.E. Krebs, R.M. Erb, B.B Yellen, B. Samanta, A. Bajaj, V.M. Rotello, E. Alsberg, 2009, Nano Letters, 9, 1812-1817.

${ }^{58}$ R. M .Bozorth, Ferromagnetism, D. Van Nostrand Company, Inc., Princeton, NJ, 1964.

${ }^{59}$ B. Berkovski, and V. Bashtovoy, Magnetic Fluids and Applications Handbook, Begell Hous. Inc., NY. 1996.

${ }^{60}$ P. Berger, N.B. Adelman, K.J Beckman, D.J. Campbell, A.B. Ellis and G.C. Lisensky, 1999, Journal of Chemical Education, 76, 943-948.

${ }^{61}$ K. Raj and A.F. Chorney, 1998, Journal of Engineering and Material Science, 372389.

${ }^{62}$ L.D. Mao and H. Koser, 2006, Nanotechnology 17, 34-47.

${ }^{63}$ A.R. Kose, B. Fischer, L. Mao and H. Koser, 2009, Proceedings of the National Academy of Sciences, 51, 21478-21483.

${ }^{64}$ D. Kramer, 2018, Nature Education. Retrieved on July 28, 2018 from https://www.nature.com/scitable/blog/bio2.0/discovering_new_cell_types_one 65 Y. Fujita, K. Kojima, N. Hamada, R. Ohhashi, Y. Akao, Y. Nozawa, T. Deguchi, M. Ito, 2008, Biochemical and Biophysical Research Communications, 377, 114-119.

66 T. Zhu, R. Cheng, S.A. Lee, E. Rajaraman, M.A. Eiteman, T.D. Querec, E.R. Unger, and L. Mao, 2012, Microfluidics and Nanofluidics, 13, 645-654.

${ }^{67}$ Thermo Fisher, 2018, Retrieved on June 28, 2018, https://www.thermofisher.com/order/catalog/product/L3224

68 M. Hejazian, N.T. Nguyen, 2015, Lab on a Chip, 15, 2998-3005. 
69 J. Zeng, C. Chen, P. Vedantam, T.R. Tzeng and X. Xuan, 2013, Microfluidics and Nanofluidics, 15, 49-55.

${ }^{70}$ A.S. Utada, A. Fernandez-Nieves, J.M Gordillo, and D. Weitz, 2008, Physical Review Letters, 100, 1-4.

${ }^{71}$ C. Clanet, J.C. Lasheras, 1999, Journal of Fluid Mechanics, 383, 307-326.

${ }^{72}$ FerroTech, 2018, Retrieved on July 292018 from

https://ferrofluid.ferrotec.com/products/ferrofluid-emg/oil/emg-911/

${ }^{73}$ S. Broersma, 1949, The Journal of Chemical Physics, 17, 873-82.

${ }^{74}$ J. Kim, J. Won, and S. Song, 2014, Biomicrofluidics, 8, 1-9.

${ }^{75}$ R.E. Rosensweig, 2013, Ferrohydrodynamics, Courier Corporation.

${ }^{76}$ R. Cheng, T. Zhu and L. Mao, 2014, Microfluidics and Nanofluidics 16, 1143-1154.

77 T. Jing, R. Ramji, M.E. Warkiani, J. Han, C.T. Lim CT, C.H. Chen, 2015, Biosensors and Bioelectronics, 66, 19-23.

${ }^{78}$ Sigma-Aldrich, 2018, Retrieved on July 292018 from https://www.sigmaaldrich.com/catalog/product/sial/74964?lang=en\&region=CA

${ }^{79}$ K. Kojima, R. Ohhashi, Y. Fujita, N. Hamada, Y. Akao, Y. Nozawa, T. Deguchi, and M. Ito, 2008, Biochemical and Biophysical Research Communications. 373, 423-428.

${ }^{80}$ V. Chokkalingam, J. Tel, F. Wimmers, X. Liu, S. Semenov, J. Thiele, C.G. Figdor and W.T. Huck, 2013, Lab on a Chip, 13, 4740-4744.

${ }^{81}$ P. Kumaresan, C.J. Yang, S.A. Cronier, R.G. Blazej, R. A. Mathies, 2008, Analytical Chemistry, 80, 3522-3529

${ }^{82}$ S. Köster, F.E. Angile, H. Duan, J.J. Agresti, A. Wintner, C. Schmitz, A.C. Rowat, C.A. Merten, D. Pisignano and A.D. Griffiths, 2008, Lab on a Chip, 8, 1110-1115. 
${ }^{83}$ J. Zeng, C. Chen, P. Vedantam, T.R. Tzeng and X. Xuan, 2013, Microfluidics and Nanofluidics, 15, 49-55.

${ }^{84}$ M. Hejazian, N.T. Nguyen, 2015, Lab on a Chip, 15, 2998-3005. 